\title{
Identification of growth mechanisms in metamorphic garnet by high-resolution trace element mapping with LA-ICP-TOFMS
}

\author{
Daniela Rubatto ${ }^{1}$, Marcel Burger ${ }^{2}$, Pierre Lanari ${ }^{1}$, Bodo Hattendorf ${ }^{2}$, \\ Gunnar Schwarz ${ }^{2}$, Christoph Neff², Peter Keresztes Schmidt ${ }^{2}$, Jörg \\ Hermann ${ }^{1}$, Alice Vho ${ }^{1}$, Detlef Günther ${ }^{2}$
}

1. Institute of Geological Sciences, University of Bern, Bern, CH-3012, Switzerland

2. Laboratory of Inorganic Chemistry, Department of Chemistry and Applied Biosciences, ETH, Zurich, CH- 8093, Switzerland

ORCID ID

Rubatto: 0000-0002-7425-7904

Burger: 0000-0002-9904-2547

Lanari: 0000-0001-8303-0771

Hattendorf: 0000-0001-9991-2410

Schwarz: 0000-0003-4449-7672

Neff: 0000-0002-9369-9580

Keresztes Schmidt: 0000-0002-4519-8861

Hermann: 0000-0001-8360-3592

Vho: 0000-0003-0158-9104

Günther: 0000-0001-7867-4310

\section{Acknowledgements}

We thank Yannick Bussweiler and Andy Smye for providing constructive comments that assisted in improving the manuscript. The careful editorial handling of Othmar Müntener is acknowledged.

D. Rubatto acknowledges the financial support of the Swiss National Science Foundation (project 200021_166280 and 206021_170722). D. Günther acknowledges financial support by ETH Zurich for the development of the LAICP-TOFMS system.

Keywords: garnet, trace element maps, metamorphism, Alps, metapelite, eclogite, LA-ICP-TOFMS 


\section{ABSTRACT}

Garnet is one of the most robust and ubiquitous minerals that record element zoning during crustal metamorphism. In addition to major elements, zoning in trace elements can provide a wealth of information to document the changing conditions of garnet growth and modification. However, mapping trace elements at low concentrations, over large areas and with high resolution has remained a major challenge.

We present a comprehensive investigation of the TE distribution in garnet from three Alpine samples that underwent a complex evolution at different metamorphic conditions. The TE distribution in garnet grains is mapped in 2D in thin section with a novel approach using laser ablation inductively coupled plasma time of flight mass spectrometry (LA-ICP-TOFMS) to achieve a lateral resolution of $5 \mu \mathrm{m}$ and limits of detection for the heavy rare earth elements (REE) down to $0.2 \mu \mathrm{g} / \mathrm{g}$. Comparison with major element zoning measured by electron probe micro-analysis (EPMA) and trace elements measured by conventional LA-ICPMS spot analysis testifies to the accuracy of the measurements.

Garnet in an amphibolite-facies metapelite from Campolungo, Central Alps that recorded metamorphism to $600^{\circ} \mathrm{C}$ preserves $\mathrm{Y}+\mathrm{REE}$ trace element zoning that closely matches that of $\mathrm{Ca}$. In this sample, there is no notable diffusive modification for trace elements. Y+REE zoning is dominated by Rayleigh fractionation in the core and by the sporadic breakdown of accessory phases producing annuli in the rim of the garnet.

A granulite-facies garnet from Malenco, Eastern Central Alps, formed during subsolidus heating, followed by peritectic melting reactions up to temperatures of $800-850^{\circ} \mathrm{C}$. Major and trace element zoning are decoupled indicating diffusional resetting of major elements, whereas trace elements still largely document the growth history. Enrichment of trace elements in the garnet mantle may be related to the consumption of biotite $(\mathrm{V}, \mathrm{Cr})$ and the dissolution of zircon (Zr) and monazite $(\mathrm{Y}+\mathrm{REE})$ in the melt. Diffusion of $\mathrm{Y}+\mathrm{HREE}$ at the core-mantle boundary occurred over a length scale of $\sim 200 \mu \mathrm{m}$. 
Garnet in an eclogite from the Sesia Zone, Western Alps (P 2 GPa, T $600^{\circ} \mathrm{C}$ ) displays pronounced fluid-related veinlets, visible in $\mathrm{FeO}, \mathrm{MgO}$ and $\mathrm{MnO}$, which cross-cut the primary growth zoning. Surprisingly, complex Y+REE and Cr zoning is not affected by the veinlets, indicating that they did not form by a crack-seal mechanism but are rather related to a selective replacement process.

The trace element maps provide a detailed insight into the growth and modification of garnet and thus allow assessment of equilibrium versus disequilibrium processes, and assist in determination of P-T conditions, garnet dating, diffusion modelling as well as documenting fluid-induced modifications.

\section{Introduction}

Geological processes in the solid Earth are recorded in the structure and composition of minerals. Variations in composition within a mineral (zoning) reflect changes in the conditions of growth (pressure $(P)$, temperature $(T)$, reactive bulk composition (X), fluids, etc.), which in turn can be traced back to physical and chemical processes in the growth environment. Mineral zoning can be observed in major and trace elements (TE, mass fractions below $1000 \mu \mathrm{g} / \mathrm{g}$ ), and while the first is broadly understood and modelled to reconstruct P-T-X paths, the zoning in TE in a number of minerals is still underexplored and poorly comprehended.

Many TE have the advantage over major elements of i) being more robust to resetting by diffusional re-equilibration at high temperature and thus better preserving growth zoning (Hermann and Rubatto 2003), and ii) exhibiting large variations in concentrations during mineral formation and subsequent growth. The study of TE in minerals has allowed, for example, to reconstruct melt compositions (van Westrenen and Draper 2007), determine time scales of magmatic and metamorphic processes (e.g. Chakraborty 2006), calculate the temperature of mineral growth (e.g. Ferry and Watson 2007), recognize formation and breakdown of coexisting phases during mineral growth (Spear and Kohn 1996; Yang and Rivers 2002), and to establish mineral equilibrium for P-T-time determination (e.g. Rubatto 2002). 
Garnet is one of the most robust minerals recording major and TE zoning. It is unsurpassed in its utility to reconstruct metamorphic P-T paths (Spear 1993; Caddick et al. 2010) on the basis of major element zoning. The investigation of TE in garnet is relatively mature (Hickmott et al. 1987; Spear and Kohn 1996; Otamendi et al. 2002; Hermann and Rubatto 2003; Skora et al. 2006; KonradSchmolke et al. 2008; Kelly et al. 2011; Moore et al. 2013; Ague and Axler 2016). The reasons for investigating TE distribution and zoning in garnet is multi-fold, from deducing metamorphic reactions (Spear and Kohn 1996; Pyle and Spear 1999; Moore et al. 2013), to the determination of geological rates based on element diffusivity (Jollands et al. 2018), to distribution of Sm and Lu to assist garnet geochronology (Anczkiewicz et al. 2007; Kelly et al. 2011; Anczkiewicz et al. 2014; Bloch et al. 2015; Guilmette et al. 2018), to equilibrium partitioning with zircon and monazite to reconstruct P-T-time paths (Hermann and Rubatto 2003; Rubatto and Hermann 2007; Taylor et al. 2014; Taylor et al. 2017).

Previous studies have proposed different processes to explain the observed TE distribution in garnet. Rayleigh-type fractionation during prograde garnet growth (at least for compatible elements such as $\mathrm{Y}$ and heavy rare earth elements - Y+HREE) should produce a monotonic decrease in such elements (i.e. "bell-shaped" mass fraction profile; Otamendi et al. 2002). This is however not always observed, particularly at subsolidus conditions, and alternative models to explain complex TE zoning have been proposed: (i) TE supply regulated by episodic breakdown of other TE-bearing phases, including accessory minerals (Hickmott et al. 1987; Pyle and Spear 1999; Yang and Rivers 2002; KonradSchmolke et al. 2008; Moore et al. 2013; Raimondo et al. 2017); (ii) differential supply of TE limited by diffusion in the matrix (Skora et al. 2006; Moore et al. 2013); (iii) inherited TE distribution from pre-existing phases in the site of garnet growth (Hirsch et al. 2003; Moore et al. 2013; George et al. 2018); (iv) solubility of TE in an intergranular fluid (Moore et al. 2013); and (v) possibly replacement of garnet along fractures and irregular domains by a second garnet generation, as shown for major elements (Pollok et al. 2008; Giuntoli et al. 2018). Understanding if key TE in garnet are distributed according to equilibrium processes, or to disequilibrium limited by diffusion and other phase stability, or if they are modified by secondary replacement is fundamental in the 
interpretation of mineral dates, thermometry and thermodynamic modelling (Lanari and Engi 2017). Discerning between these processes in natural samples requires high-resolution imaging of the TE distribution within garnet grains.

Most commonly, TE mineral composition is determined using laser ablation inductively coupled plasma mass spectrometry (LA-ICPMS) in spot analyses and line profile mode, whereas mapping (here intended as 2D images where the ablation crater's depth is smaller than its diameter) is in its infancy (Ulrich et al. 2009; Raimondo et al. 2017; George et al. 2018; Hyppolito et al. 2019). This onedimensional documentation has limited our understanding of how TE are distributed within garnet and which zoning can be considered typical for certain growth processes (Moore et al. 2013). In the same way that electron microprobe mapping revolutionized the understanding of mineral zoning for diffusion and thermodynamic studies, the mapping of TE zoning can make a substantial difference in the understanding of TE systematics as petrogenetic indicators and of mechanisms of mineral growth during metamorphism.

Certain TE are amenable to mapping by electron microprobe analysis at the 100 $\mu \mathrm{g} / \mathrm{g}$ level (P and Y, more rarely $\mathrm{Cr}$ and Sc) (Spear and Kohn 1996; Yang and Rivers 2002; Moore et al. 2013). Other studies have used secondary ion mass spectrometry for the analysis of partial or full sets of TE in garnet at the $0.1 \mu \mathrm{g} / \mathrm{g}$ level (Hickmott et al. 1987; Green et al. 2000; Skora et al. 2006; Moore et al. 2013), but this method is time-consuming and relies heavily on appropriate matrix-matched standards. In the last 15 years, TE mapping by LA-ICPMS has been optimized for geological materials (Woodhead et al. 2007; Ulrich et al. 2009), but its application to garnet is still very limited (Ulrich et al. 2009; Raimondo et al. 2017; George et al. 2018; Guilmette et al. 2018). Even more recently, LA-ICP-TOFMS instrumentation has been developed to achieve rapid acquisition of composition maps for all elements at high lateral resolution (Gundlach-Graham et al. 2015; Bussweiler et al. 2017, Burger et al. 2017; Burger et al. 2019) and the first applications to geological materials have been published (Gundlach - Graham et al. 2018; Bussweiler et al. 2019; Ubide et al. 2019). The major advantage of LA-ICP-TOFMS is its quasi-simultaneous acquisition of complete mass spectra at high repetition rates. In combination with low- 
dispersion aerosol transport systems (Wang et al. 2013), it allows for rapid and sensitive element mapping.

In this contribution we present mapping of the TE zoning in garnet using LA-ICPTOFMS. We investigate the distribution of a large set of TE at a high lateral resolution of $5 \mu \mathrm{m}$ in three garnet grains that represent examples of contrasting metamorphic conditions with respect to T, P and relation to major elements. (1) Garnet from an amphibolite-facies metapelite from the Central Alps grew during two orogenic cycles at T-time conditions at which diffusion of major elements is negligible $\left(<600^{\circ} \mathrm{C}\right)$, allowing direct comparison of major and TE zoning. (2) Garnet in granulite-facies metapelite from Malenco (Eastern Central Alps) records a single metamorphic cycle over at least 20 My reaching maximum $\mathrm{T}$ of $850^{\circ} \mathrm{C}$, which has erased major element zoning, whereas TE zoning is preserved. (3) Garnet in a low temperature eclogite (1.8-2.3 GPa and $520-600{ }^{\circ} \mathrm{C}$ ) from the Sesia Zone in the Western Alps shows major element zoning with secondary garnet replacement cross-cutting the initial growth zoning. The record of different behaviour of TE in these three samples sheds light on the mechanism of garnet growth, equilibration, and replacement, which provides fundamental insights into crustal metamorphic processes.

\section{Geological background and sample description}

Sample CLM6 is from the Campolungo locality (N 46²7'60", E $8^{\circ} 42^{\prime} 54^{\prime \prime}$ ) in the Swiss Central Alps. The Mesozoic sediments at Campolungo document amphibolite-facies conditions during Barrovian metamorphism at $\mathrm{T}$ of $\sim 600{ }^{\circ} \mathrm{C}$ and $\mathrm{P}$ of $0.5-0.65 \mathrm{GPa}$ at peak T (Todd and Engi 1997). The studied sample is from a paragneiss unit that is tectono-stratigraphically situated below the Mesozoic sediments. The sample was previously investigated by Boston et al. (2017) who reported major element zoning in the garnet during two distinct metamorphic cycles. Boston et al. (2017) obtained monazite ages of $332 \pm 4 \mathrm{Ma}$ for sample CLM6 and allanite ages between 32 and 28 Ma for a nearby Mesozoic metasediment. They concluded that the paragneiss unit underwent lower amphibolite-facies metamorphism during the Variscan orogeny and was again metamorphosed at amphibolite facies during the Alpine collision. On the 
contrary, Gieré et al. (2011) interpreted the garnet growth in similar metapelites from the Campolungo area as solely grown during Alpine metamorphism, although without any geochronological constraints. The P-T-time reconstructed by Boston et al. (2017) suggests that the sample remained at $\mathrm{T}$ of $500-600{ }^{\circ} \mathrm{C}$ for $\sim 15 \mathrm{My}$ (from 33 to $18 \mathrm{Ma}$ ) during the Alpine orogeny. Fast cooling in the order of $>100^{\circ} \mathrm{C} / \mathrm{Ma}$ occurred after $18 \mathrm{Ma}$ (Boston et al. 2017). The duration of Barrovian metamorphism in this unit during Variscan orogeny is unknown but likely on the order of several My.

The sample mineral assemblage consists of quartz, white mica, biotite, plagioclase, garnet (15\% in volume), staurolite and minor kyanite and graphite, with accessory monazite and zircon. The investigated garnet is euhedral and has a diameter of $\sim 5 \mathrm{~mm}$ (Online Resource Fig. S1a). It is wrapped by a foliation defined by mica, quartz, plagioclase and graphite; it is mainly in direct contact with biotite, white mica and quartz. In the core, it contains an internal foliation defined by inclusions of fine-grained ilmenite, quartz and white mica; larger inclusions of ilmenite are in the rim, minor secondary chlorite is distributed along fractures.

Sample MG1 is from the granulite-facies metapelites of the Val Malenco area, Northern Italy (N 46²'38.1", E 948'04.3"). These metapelites are part of a lower crustal sequence that experienced extensive partial melting and melt extraction (up to 50\%, Hermann et al. 1997), leading to the formation of restitic rocks that are rich in garnet. The peak metamorphic conditions recorded are 1.0 GPa and $800-850^{\circ} \mathrm{C}$ (Hermann et al. 1997; Müntener et al. 2000). The timing of protracted high-T metamorphism and partial melting in the metapelites is constrained by $\mathrm{U}-\mathrm{Pb}$ dating of monazite and zircon to 281-257 Ma (Hermann and Rubatto 2003). Hermann and Rubatto (2003) reported flat major element zoning in large garnet cores and a small overgrowth at the rim. In contrast to major elements, the garnet cores display marked Y and HREE zoning. Based on garnet composition and inclusion assemblages Hermann and Rubatto (2003) concluded that garnet growth may have started at subsolidus amphibolite facies $\left(600^{\circ} \mathrm{C}\right)$, but most of the preserved garnet grew in a 20 My period at $\mathrm{T}$ of $700-$ 
$850^{\circ} \mathrm{C}$ in the presence of melt (their zone $1-2$ ), with a minor Ca-rich rim (zone 45) forming during isobaric cooling and reaction with plagioclase.

Sample MG1 has a granoblastic texture with an assemblage of garnet (50\% in volume), quartz, plagioclase (largely retrogressed to chlorite, clinozoisite and white mica), biotite (partly retrogressed to chlorite) and kyanite, with accessory rutile, zircon, monazite and pyrrhotite (Online Resource Fig. S1b). The analysed garnet is subhedral, $1.5 \mathrm{~mm}$ in diameter, and is surrounded by more or less altered plagioclase, with minor rutile. It contains inclusions of altered plagioclase and biotite; secondary mica fills the fractures.

Sample AV16021 (hereafter AV) is from the Ivozio Complex (Zucali et al. 2004; Delleani et al. 2018) at the eastern border of the Sesia Zone (Western Alps, Italy). The Sesia Zone consists of a basement that underwent Variscan metamorphism in the Carboniferous and that was intruded by Permian bimodal magmatism. This basement experienced eclogite facies metamorphism during Alpine subduction in the late Cretaceous (Rubatto et al. 2011). The banded texture in the eclogites and the overall abundance of mafic rocks in the Ivozio Complex suggests a gabbroic body as protolith (Zucali et al. 2004). The P-T path of the Ivozio metabasites during the Alpine metamorphism is characterized by a multistage evolution (Zucali and Spalla 2011). Garnet growth was protracted from $1.1 \mathrm{GPa}$ and $500^{\circ} \mathrm{C}$ to peak conditions of $1.8-2.3 \mathrm{GPa}$ and $520-600{ }^{\circ} \mathrm{C}$. Zircon dating in the surrounding micaschists (Rubatto et al. 1999) and allanite dating in a mafic rock (Vho 2020) constrains prograde to peak metamorphism of this unit to $\sim 68-60 \mathrm{Ma}$.

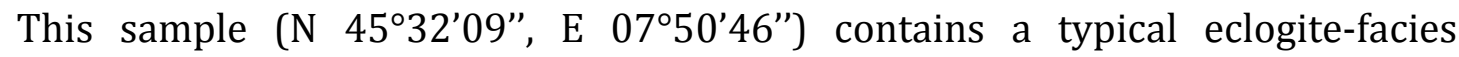
assemblage and is characterized by (i) mafic layers rich in garnet (ca. 40\%), omphacite and glaucophane, with minor rutile, white mica and pyrite, and (2) quartz-rich domains with garnet (20-30\%), white mica, omphacite and glaucophane. The analysed garnet grain (Online Resource Fig. S1c) is $1.4 \mathrm{~mm}$ in diameter; it is surrounded mostly by quartz and minor omphacite, white mica and zoisite, and contains inclusions of quartz, zoisite, white mica and minor rutile. There is no previous study of the TE distribution in garnet in this unit. 
In each sample, the investigated grains are large relative to other grains in the same sample, and are thus most likely to show the complete zoning sequence. Indeed, the selected garnet grains in CLM6 and MG1 show all the zones in major and TE that were identified by previous studies based on multiple garnet grains (Hermann and Rubatto 2003; Boston et al. 2017).

\section{Methods}

\section{EPMA mapping}

X-ray compositional maps were acquired by electron probe micro analysis (EPMA). They are presented as standardized mass fraction maps of oxide weight percentage obtained using the program XMAPTooLS 3.2.2 (Lanari et al. 2014; Lanari et al. 2019). X-ray mapping was carried out using a JEOL JXA-8200 SuperProbe at the Institute of Geological Sciences of the University of Bern following the analytical procedure described in Lanari and Piccoli (2019). The maps for garnet CLM6 and MG1 were acquired after LA-ICP-TOFMS analysis and minor repolishing (a few $\mu \mathrm{m}$ ) of the thin sections. Acquisition was at $15 \mathrm{keV}$ accelerating voltage using a specimen current of $100 \mathrm{nA}$, dwell times of $210 \mathrm{~ms}$ (CLM6), $250 \mathrm{~ms}$ (MG1), a step size of $8 \mu \mathrm{m}$ and a beam diameter of $1 \mu \mathrm{m}$. The spot analyses used as reference standards were acquired at $15 \mathrm{keV}$ accelerating voltage using a specimen current of $20 \mathrm{nA}$, dwell times of $20 \mathrm{~s}$ and $2 \times 10 \mathrm{~s}$ for peak and background with a beam diameter of $1 \mu \mathrm{m}$. Oxide mass fractions were calculated using the CITZAF routine and the following synthetic and natural standard reference materials: garnet $\left(\mathrm{SiO}_{2}, \mathrm{Al}_{2} \mathrm{O}_{3}\right)$, olivine $(\mathrm{MgO}, \mathrm{FeO})$, anorthite $(\mathrm{CaO})$, tephroite $(\mathrm{MnO})$ and ilmenite $\left(\mathrm{TiO}_{2}\right)$.

The CLM6 garnet was imaged across an area of 8 × $8 \mathrm{~mm}$ using wavelength dispersive spectroscopy (WDS) for $\mathrm{Mg}, \mathrm{Ca}, \mathrm{Mn}, \mathrm{Al}, \mathrm{Fe}$ and energy dispersive spectroscopy (EDS) for $\mathrm{P}, \mathrm{S}, \mathrm{Si}, \mathrm{Al}, \mathrm{Ti}, \mathrm{Na}, \mathrm{K}$ and $\mathrm{Ni}$. The composition maps of $\mathrm{SiO}_{2}$, $\mathrm{TiO}_{2}, \mathrm{Al}_{2} \mathrm{O}_{3}, \mathrm{FeO}, \mathrm{MnO}, \mathrm{MgO}$ and $\mathrm{CaO}$ were obtained using 60 fully quantified spot analyses.

The MG1 garnet was mapped across an area of $5 \times 6 \mathrm{~mm}$ using WDS for $\mathrm{Mg}, \mathrm{Ca}$, $\mathrm{Mn}, \mathrm{Al}, \mathrm{Fe}$ and EDS for $\mathrm{P}, \mathrm{S}, \mathrm{Zr}, \mathrm{Si}, \mathrm{Al}, \mathrm{Ti}, \mathrm{Na}$ and $\mathrm{K}$. The compositional maps of 
$\mathrm{SiO}_{2}, \mathrm{TiO}_{2}, \mathrm{Al}_{2} \mathrm{O}_{3}, \mathrm{FeO}, \mathrm{MnO}, \mathrm{MgO}, \mathrm{CaO}$ were obtained using 45 fully quantified spot analyses.

The AV garnet grain mapped for major elements is not the same as that investigated for TE, but a very similar one from the same sample (as shown below). Acquisition conditions were similar to the other samples and with a dwell time of 150 ms. EPMA mapping covered an area of $2.40 \times 2.19 \mathrm{~mm}$ using WDS for Si, Mg, Ca, Mn, Al, Fe, Ti Na, K and EDS for P, S, Ni, La, Ce, Zr and Au. The compositional maps of $\mathrm{SiO}_{2}, \mathrm{TiO}_{2}, \mathrm{Al}_{2} \mathrm{O}_{3}, \mathrm{FeO}, \mathrm{MnO}, \mathrm{MgO}$ and $\mathrm{CaO}$ were obtained using 27 fully quantified spot analyses.

\section{LA-ICP-TOFMS mapping}

Element mapping was carried out using a $193 \mathrm{~nm}$ ArF excimer laser ablation system (GeoLas C, Lambda Physik AG, Goettingen, Germany) coupled to an ICPTOFMS (icpTOF, TOFWERK AG Thun, CH) equipped with a high capacity interface pump (UNO 065 D, Pfeiffer, DE) at ETH Zurich. Laser ablation sampling was performed in a custom-built, low-dispersion aerosol transport system that provided single pulse transient signal durations of less than $10 \mathrm{~ms}$ (FW0.01M) for laser spot diameters $\leq 10 \mu \mathrm{m}$ (Gundlach-Graham et al. 2015). The data for the three garnets was acquired over a time span of almost two years and experiments differed considerably. To an extent, this also reflects the distinct steps in method development accomplished over this time.

Garnet CLM6 was mapped using a method described earlier (Burger et al. 2017). Briefly, 60 adjacent sections of 25 parallel lines each were ablated. The individual sections were vertically concatenated during data post-processing to generate the full image. The laser fluence was $15 \mathrm{~J} / \mathrm{cm}^{2}$, a repetition rate of 100 $\mathrm{Hz}$, a circular ablation spot size $5 \mu \mathrm{m}$ in diameter and a scan rate of $500 \mu \mathrm{m} / \mathrm{s}$ were employed for edge-to-edge sampling across an area of 8 × $7.5 \mathrm{~mm}$ or 2.4 million pixels (Mpx). The total image acquisition lasted 12 hours. At this stage, laser ablation and ICP-TOFMS were not synchronized, and acquisition of individual sections was manually started. The ICP-TOFMS was operated with its multi-notch filter to attenuate the plasma background ions ${ }^{40} \mathrm{Ar}^{+}$and ${ }^{40} \mathrm{Ar}_{2}{ }^{+}$to levels <400'000 cps. This was to avoid saturation of the micro-channel plate 
detector, but it also affected the transmission of nearby isotopes of lower $\mathrm{m} / \mathrm{z}$ in particular. During data processing, it was found that Al and Si were too strongly biased to be evaluable and excluded from the quantification (see below). A vertical tilt of the sample surface was compensated for by manually refocusing the laser at the beginning of each individual subsection. A correction of horizontal tilt was however not possible at that stage. However, the quantified images suggest that there is no substantial impact of lateral tilt on data quality with respect to the geological interpretation (see "Results" and "Discussion").

For imaging the second garnet MG1, the icpTOF's reaction cell was pressurized with hydrogen gas to reduce argon-based background species and molecular ions (Burger et al. 2019) without having to employ the multi-notch filter. Thereby, lower limits of detection (LOD) could be achieved for Al, Si and Ca in particular. Further improvements over the previous analyses included triggered acquisition of individual subsections, which enabled considerable automation of the measurements. The sample was imaged across an area of $7.3 \times 6.6 \mathrm{~mm}(1.9$ $\mathrm{Mpx}$ ) in 88 equally sized subsections at a laser repetition rate of $50 \mathrm{~Hz}$. The dimensions of the displayed image are $6.25 \times 6.25 \mathrm{~mm}$ because areas surrounding the garnet were of no particular interest and were therefore cropped during image processing. The fluence of the laser was $20 \mathrm{~J} / \mathrm{cm}^{2}$. Total acquisition lasted 15 hours. The reaction cell in the ICP-TOFMS was fed with an $\mathrm{H}_{2}$ gas flow rate of $2.5 \mathrm{~mL} / \mathrm{min}$ throughout. During the experiment, however, an accidental interruption of the carrier gas flow occurred. This caused 25 lines of the image to be lost (black lines at 2/3 of the garnet height). A tilt of the sample surface in the vertical direction was corrected for by constantly adjusting the laser focus between the beginning of the first and the last line of the image, respectively. No tilt correction was necessary in the horizontal direction.

Finally, element imaging for the AV garnet was performed using the ICP-TOFMS with extended drift tube (icpTOF 2R, Tofwerk, Thun, $\mathrm{CH}$ ) providing higher mass resolving power. The ablation strategy involved a hole-drilling approach for which the isotope signals for each individual pixel were obtained by firing 25 laser pulses at the same position using a spot diameter of $5 \mu \mathrm{m}$ and a frequency of $100 \mathrm{~Hz}$, before moving the sample to the next, adjacent position. While this strategy decreases data acquisition speed per unit area, sensitivities and LOD can 
be substantially improved. This is a direct consequence of the increase in the amount of material sampled. The garnet was mapped across an area of 1 x $2 \mathrm{~mm}$ (i.e. $80 \mathrm{kpx}$ ) and collected in 8 equally sized subsections arranged in a 2 x 4 grid, lasting 7.5 hours. The fluence of the laser was $15 \mathrm{~J} / \mathrm{cm}^{2}$. In addition to argon background species ${ }^{40} \mathrm{Ar}^{+}$, and ${ }^{40} \mathrm{Ar}_{2}{ }^{+}$, also ${ }^{56} \mathrm{Fe}^{+}$was attenuated via the multinotch filter to prevent detector saturation.

The laser craters' depths were not measured directly. Considering the $50 \%$ lower ion signals compared to SRM NIST 610, however, we assume the depth ablation rate to be correspondingly lower. For SRM NIST 610, a depth ablation rate between 200 and $300 \mathrm{~nm} /$ pulse has been determined for a fluence of 15 $25 \mathrm{~J} / \mathrm{cm}^{2}$ with the same laser ablation system (Horn et al. 2001). The material removed from garnets CLM6 and MG1 is thus considered to originate from a depth of less than $200 \mathrm{~nm}(1 \mathrm{pulse} /$ pixel) and less than $5 \mu \mathrm{m}$ for garnet AV (25 pulses).

The data acquisition protocol and data processing routines have been described in more detail in a previous publication (Burger et al. 2017). Briefly, the mass calibration was verified and mass spectra were baseline-subtracted using Tofware (versions 2.5.10 and 2.5.11, Tofwerk AG, Thun). In-house written MATLAB scripts (version R2015a, Mathworks, MA) were then used for calculation of gas-blank-subtracted time traces, integration of signal intensities for individual pixels and their assignment to sample position. For the processing of the AV garnet data, the MATLAB routines had been incorporated in an inhouse written Python 3 software suite.

Quantification of each pixel was based on relative sensitivity factors established through external calibration with the standard reference material NIST SRM 610 and a normalization of the mass fractions of all determined element oxides (Liu et al. 2008). Because $\mathrm{Al}$ and Si were biased through the use of the multi-notch filter, quantification of garnet CLM6 was done by excluding the mass fractions of $\mathrm{Al}_{2} \mathrm{O}_{3}$ and $\mathrm{SiO}_{2}$ from the normalization. Electron probe microanalyses from this sample had revealed a homogeneous distribution of both elements at mass fractions of $21.0 \% \mathrm{Al}_{2} \mathrm{O}_{3}$ and $37.5 \% \mathrm{SiO}_{2}$. Element-oxide mass fractions determined by LA-ICP-TOFMS were thus normalized to the remaining $41.5 \%$. 
The gas blank intensities were assumed to represent the instrumental background. LOD were then estimated using counting statistics and the mean sensitivity of the elements detected during the mapping. Sensitivities were typically found to decrease by $30 \%$ to $60 \%$ during the acquisition of a map. This drift is assumed to originate mainly from drift in the ICP-TOFMS system and changes in laser energy reaching the sample surface. The sensitivity drift affects the pixels' signal/noise ratios $(\mathrm{S} / \mathrm{N})$ while element mass fractions and their ratios in particular are not considered to be affected substantially.

\section{Results}

\section{Major element zoning}

LA-ICP-TOFMS maps were produced for all elements including major, minor and TE. In all samples $\mathrm{Ca}, \mathrm{Mg}$ and $\mathrm{Mn}$ maps best describe garnet major element zoning (Fig. 1-3). The LA-ICP-TOFMS maps for major elements generally reproduce the EPMA maps.

In CLM6 garnet, the EPMA-CaO map shows a euhedral concentric zoning in the core and mantle, from Ca-rich core to Ca-poor mantle, truncated by an irregular boundary to a homogeneous, Ca-poor rim (Fig. 1d). Both the euhedral Ca-rich core and the irregular mantle-rim boundary are recognizable in the LA-ICPTOFMS-CaO map. The EPMA-MnO map (Fig. 1a) shows a diffuse zoning at the core-mantle transition (less pronounced euhedral core) and does not identify the irregular mantle-rim boundary. The LA-ICP-TOFMS-MnO map (Fig. 1b) is remarkably similar to the EPMA-MnO map. A line profile across the grain in MnO in both maps shows their close correspondence (Fig. 1c).

For garnet CLM6, the LA-ICP-TOFMS major element maps show analytical artefacts in the form of parallel bands with less uniform mass fractions for $\mathrm{CaO}$ in the core and mantle in particular (Fig. 1e). This is a result of an imperfectly mounted thin section, causing the laser to become slightly de-focused during individual sections analysed in a sequence. Together with the comparably low $\mathrm{S} / \mathrm{N}$ obtained for Ca during these analyses, the change in ablated mass led to an underestimation of the $\mathrm{CaO}$ content. After re-focusing at the start of a new 
sequence, the $\mathrm{S} / \mathrm{N}$ increased quantification improved. Although these artefacts are present in all maps including the TE, they are clearly distinguishable from the true element zoning and thus do not affect the interpretation of the TE maps substantially.

The major element zoning depicted by the EPMA maps is less complex for the high-T garnet MG1 (Fig. 2 and Online Resource Fig. S2), which is composed of two homogeneous zones with a sharp boundary: (i) a large core that is nearly homogeneous in $\mathrm{CaO}, \mathrm{MgO}$ and $\mathrm{MnO}$ (a very weak $\mathrm{CaO}$ outwards decrease is visible, Fig. 2d); (ii) a thin, discontinuous rim (5-50 $\mu \mathrm{m}$ across, left side and upper right corner, Fig. 2a and d) that is rich in $\mathrm{CaO}$ and poor in $\mathrm{MnO}$ and $\mathrm{MgO}$. The LA-ICP-TOFMS maps (Fig. $2 \mathrm{~b}$ and e) for the same elements show comparable zoning to those obtained by EPMA.

In the eclogitic sample AV, the garnet grain mapped by EPMA (Fig. 3) is a nearby grain with a comparable composition and zoning to the one analysed by LA-ICPTOFMS. Still, core, mantle and rim composition obtained for the two different grains agreed within $0.1 \mathrm{wt} \%$ for major element oxides. The grain is characterized by a primary zoning pattern truncated by secondary radial features (Fig. 3, also see comparable features in the LA-ICP-TOFMS Mn and Mg maps discussed below). $\mathrm{CaO}, \mathrm{MnO}$ and $\mathrm{FeO}$ generally decrease from core to rim, whereas MgO increases (Fig. 3). The central part of the core, particularly rich in inclusions, is poor in $\mathrm{FeO}$ and $\mathrm{MnO}$ and richer in $\mathrm{MgO}$ with respect to the rest of the core and similar to the rim composition. However, this feature is not visible in $\mathrm{CaO}$ (Fig. 3a). A broad rim of $\sim 200 \mu \mathrm{m}$ is rather homogeneous in composition, with relatively higher $\mathrm{MgO}$ and lower $\mathrm{CaO}, \mathrm{FeO}$ and $\mathrm{MnO}$. This main core-rim zoning is parallel to the euhedral garnet shape indicating that it represents primary growth zoning. This main zoning pattern is truncated by irregular linear features (hereafter veinlets) from 10 to $100 \mu \mathrm{m}$ in width that run radially from rim to core and are similar to "healed cracks". The veinlets are marked by distinct compositional changes in $\mathrm{MgO}, \mathrm{MnO}$ and $\mathrm{FeO}$, which are not observed for $\mathrm{CaO}$. 


\section{Trace element zoning}

Different types of zoning patterns can be recognized among the TE. In the following description of TE zoning in garnet the different substitution mechanisms for TE in garnet should be kept in mind. In the general garnet structure $\mathrm{X}_{3} \mathrm{Y}_{2} \mathrm{Z}_{3} \mathrm{O}_{12}$ the main substitutions are (i) divalent cations such as $\mathrm{Zn}$ and Co on the eight-coordinated X-site for Mg and Fe; (ii) trivalent Y+REE on the Xsite for $\mathrm{Ca}$; (iii) $\mathrm{Ti}^{4+}$ and trivalent $\mathrm{V}$ and $\mathrm{Cr}$ on the six-coordinated (octahedral) $\mathrm{Y}$ site for $\mathrm{Al}$; (iv) $\mathrm{P}^{5+}$ and $\mathrm{Ge}^{4+}$ on the foru-coordinated (tetrahedral) Z-site.

In the amphibolite-facies garnet of CLM6, the sharp zoning defined by Ca (euhedral core, oscillatory zoning in the mantle and sharp discordant rim, best visible in the EPMA-CaO map, Fig. 1d) is reflected in numerous elements such as Sc, Y and the detectable REE from Eu to Lu (Fig. 4). The match between the Y+HREE zoning and the $\mathrm{CaO}$ zoning of the EPMA map is remarkable: the sharp boundaries, the fine fractures and annuli defined by $\mathrm{CaO}$ zoning are reproduced in the Y+HREE images, both in shape and position. Among the Y+HREE there is no distinguishable difference in the location of sharp zoning features such as the euhedral inner core or the annulus in the outer core (Fig. 4 and 5).

Some of the zoning features, particularly the discordant mantle-rim boundary, are also visible in P (Fig. 4), which shows a weak inverse zoning with respect to Ca, $\mathrm{Y}$ and REE: the core is poorer in P than the mantle and rim. Notably, the diffuse zoning of $\mathrm{Mg}$, Fe and $\mathrm{Mn}$ in the EPMA maps (Fig. 1 and Online Resource Fig. S2) is not mimicked by any of the detectable TE. Some of the TE that are below LOD in garnet (see Online Resource Table S1 for LOD), instead highlight inclusions and alteration along fractures. The metals $\mathrm{Ni}, \mathrm{Cu}, \mathrm{As}, \mathrm{Rh}, \mathrm{Ba}, \mathrm{Ta}, \mathrm{Pt}, \mathrm{Au}$, Bi and U (maps not shown) are systematically distributed along fractures and highlight a potential bias for these elements when fractures are intersected during spot or line analysis. Elements such as $\mathrm{Cu}, \mathrm{Zr}$, the light-REE (LREE), $\mathrm{Hf}, \mathrm{Pb}$, Th and $U$ are relatively incompatible elements in garnet and well mark the micro-inclusions of sulphides, zircon and monazite/allanite. Around the largest inclusions some re-deposition of material from previous laser pulses is visible as a halo (see as an example Ce, plotted in logarithmic scale in Fig. 4). 
The granulite-facies MG1 garnet has visible zoning in the core-mantle in most detectable elements, including some of the transition metals that were not detected in CLM6 garnet (Fig. 6). While there is a strong correlation between major and TE zoning in CLM6, MG1 garnet shows far more features in the TE than in the major element maps. A detailed zoning is defined by $\mathrm{Y}$, which is enriched in the core, decreases outwards, and has an outer band of enrichment (hereafter, mantle) of 50-100 $\mu \mathrm{m}$, before the truncating thin rim with low $\mathrm{Y}$ contents. This low-Y rim corresponds to the high-Ca and low-Mn rim in the major element map (Fig. 2). The mantle-rim boundary is particularly sharp, whereas the core to mantle zoning is more gradational in all elements. The full zoning is also shown by the REE Tb-Lu (Fig. 6); notably the HREE increasingly show a patchy zoning in the inner core.

A gradually decreasing concentric zoning across the core is well defined in Sc (Fig. 6) and weak in Ge (Online Resource Fig. S3), but the enrichment in the mantle is not evident. The opposite zoning with higher mass fractions in the mantle than in the core is shown in $\mathrm{V}$ and low concentrations detected for $\mathrm{Cr}$ and Zr (Fig. 6 and Online Resource Fig. S3). The mantle enrichment versus the core is also evident in the mid REE Gd and Tb, whereas HREE Ho-Lu have a higher mass fraction in the inner core than in the mantle.

The high-Ca thin rim, that is distinct in major elements, is depleted in most TE (mainly below LOD), but locally enriched in Ti, V and Cr (Fig. 6, left and top right of the crystal). Notably these elements are not equally present throughout the thin rim, but only in one corner that is in contact with altered biotite; in this area $\mathrm{Ti}, \mathrm{V}$ and $\mathrm{Cr}$ show an additional zoning within the rim.

As for sample CLM6, some elements show particularly well the inclusions of zircon and monazite with halos: these are Zr, LREE and Ce (Fig. 6, but also e.g. La and Th not shown). Elements that are not detectable and are in low mass fraction in the garnet are instead concentrated in fractures $(\mathrm{K}, \mathrm{Ti}, \mathrm{Cu}, \mathrm{Zn}, \mathrm{Rb}, \mathrm{Rh}, \mathrm{Au}, \mathrm{Sn}$, $\mathrm{Ba}, \mathrm{La}, \mathrm{Ce}, \mathrm{Pt}, \mathrm{Gd}, \mathrm{Pb}$ and $\mathrm{Bi}$ ). This is likely due to later alteration by fluids and/or mineral replacement.

In the eclogitic AV garnet, $\mathrm{Y}$ and HREE define the principal zoning with a euhedral core and progressive depletion towards the outside (Fig. 7). An equally 
euhedral rim is marked by an overall increase in $\mathrm{Y}$ and some REE with local oscillatory zoning. Most notably, the crosscutting radial veinlets characterized by higher $\mathrm{Mn}$ and lower $\mathrm{Mg}$ than the rim composition are also visible in TE such as $\mathrm{Zn}$ and Co, but do not affect the euhedral and oscillatory zoning of Y+HREE and Ti (see "Discussion").

The inclusion-rich core has an inner part with more irregular zoning, mimicking the major elements in the nearby grains (see also Fig. 3). A thin halo depleted or enriched in elements can be seen around some of the inclusions in the core; in particular, $\mathrm{V}$ is enriched at the expenses of most other elements around epidote inclusions. The external part of the rim has the highest mass fraction in Y, Dy and Ho, whereas from Tm to Lu the inner core is richer than the rim. The rim has a visible oscillatory zoning in most Y+HREE, particularly in the outer part, and a $50 \mu \mathrm{m}$ thick annulus midway across marked by Y, Ho and Er (see red arrows in the $\mathrm{Y}$ and Er maps of Fig. 7). The euhedral, but discontinuous zoning in Y+HREE suggests that the core and rim represent two distinct stages of growth, but without signs of resorption between the core and rim. The transition metals, Sc, $\mathrm{Cr}$, Co and $\mathrm{Zn}$, have zoning roughly opposite to $\mathrm{Mn}$, with flat and low mass fraction in the core of the garnet, and higher mass fractions in the rim. Co and $\mathrm{Zn}$ match particularly close the Mg zoning. $\mathrm{Ti}$ and $\mathrm{Zr}$ are the opposite, enriched in the core with respect to the rim. $\mathrm{V}$ and $\mathrm{Cr}$ have a more irregular distribution, and have patchy areas of enrichment.

\section{Discussion}

\section{Spatial resolution, detection limits and accuracy}

The LA-ICP-TOFMS setup delivers element maps that have a lateral resolution of $5 \mu \mathrm{m}$ (pixel size) compared to the 15-17 $\mu \mathrm{m}$ previously reported for LA-ICPMS images (Ulrich et al. 2009; Raimondo et al. 2017; George et al. 2018). This increased resolution approaches that of EPMA major element imaging, with comparable or shorter acquisition times. The improved lateral resolution allows for a closer investigation of diffuse versus sharp compositional zoning and of thin features like mineral replacement veinlets (see below). 
The achievable LOD are determined by the mass removed per pixel. Depending on the sampling mode, low abundant elements may not be detectable: (i) the approach used for the CLM6 garnet did not allow for detection of Zr (LOD 47 $\mu \mathrm{g} / \mathrm{g}$ ), except for several inclusions. Lower LOD could be achieved with the modes used for MG1 and AV garnets, which allowed for mapping the $\mathrm{Zr}$ distribution (LOD 20 and $3 \mu \mathrm{g} / \mathrm{g}$, respectively), which is useful to identify events of zircon dissolution in aqueous fluids and melts during garnet growth. (ii) LREE La-Pr were always below LOD (10-0.4 $\mu \mathrm{g} / \mathrm{g}$ depending on setup), but these elements are not crucial for the petrogenesis of garnet. LREE La-Pr were not detectable even by LA-ICPMS analyses at $40 \mu \mathrm{m}$ diameter laser spot size. (iii) Sm and $\mathrm{Nd}$ mass fractions are below LOD (50-2 $\mu \mathrm{g} / \mathrm{g}$ depending on setup), while analyses at $40 \mu \mathrm{m}$ spot size yielded mass fractions of $0.1-10$ and $0.2-4 \mu \mathrm{g} / \mathrm{g}$ of Sm and Nd for CLM6 and MG1 garnet (Online Resource Table S2), respectively. The distribution of Sm and $\mathrm{Nd}$ would be relevant for the interpretation of $\mathrm{Sm}-\mathrm{Nd}$ ages. Previous studies using conventional LA-ICPMS and a spot size of $15 \mu \mathrm{m}$ have not reported LOD for elements, but present coarse maps of $\mathrm{Zr}$, Sm and $\mathrm{Nd}$ (Raimondo et al. 2017; George et al. 2018).

Normalized REE patterns are a common way to analyse their relative occurrences and it is interesting to compare the REE patterns obtained with 5 $\mu \mathrm{m}$ pixel size LA-ICP-TOFMS data to those obtained using larger laser spots. The low sample mass analysed per $5 \mu \mathrm{m}$ diameter pixel limits the attainable precision of the quantification and thus the REE pattern of individual pixels appears noisier than analyses using larger spot sizes (Raimondo et al. 2017). Nonetheless, the comprehensive element maps can be used to identify contiguous regions of similar composition and thus likely similar genesis. REE patterns from integrated pixel data within such areas show smooth trends that compare well with those generated by LA-ICPMS analyses using larger spot size. Figure 8 compares the data obtained for the main zones in MG1 garnet by LAICP-TOFMS using areas of $\sim 50-600$ pixels $\left(\sim 200-2400 \mu \mathrm{m}^{3}\right.$ sample volume $)$ with those from LA-ICPMS analyses using $60 \mu \mathrm{m}$ spot size $(\sim 20 \mu \mathrm{m}$ deep, $\sim 56000 \mu \mathrm{m}^{3}$, data in Online Resource Table S2). By averaging a larger sample mass of the LA-ICP-TOFMS analyses, the patterns become very similar. The 
pattern for the M-HREE is relatively smooth and the individual features of the different regions are fully reproduced.

The reconstruction of REE composition from LA-ICP-TOFMS maps offers the advantage that, even for zones with low mass fractions, accurate REE patterns can be constructed, if a sufficiently large area can be identified. Using XMapTools, data from areas of variable size and shape can be extracted while avoiding areas with multiple inclusions (Lanari and Piccoli 2019). Additionally, the REE data represent the near surface composition and mitigates artefacts from unrecognized inclusions at sub-surface levels, which would be sampled in LAICPMS spot analyses at greater depths. This is demonstrated for sample AV, where the garnet's TE mass fractions in the core could not be obtained via conventional spot analysis because of the high number of inclusions, mainly epidote. Using the area sampling approach smooth REE pattern can be extracted for all domains (Fig. 9)

\section{Diffusion versus growth zoning}

Diffusion of major and TE can be assessed relative to each other by comparing maps and traverses across garnets CLM6 and MG1, for which better constraints for the temperature and duration of metamorphism exist.

In sample CLM6, Ca preserves pronounced zoning that matches that of $\mathrm{Y}$ and $\mathrm{P}$ (Fig. 1, 4 and 5), which are slow diffusing TE (Spear and Kohn 1996; Yang and Rivers 2002; Ague and Axler 2016; Jollands et al. 2018; Higashino et al. 2019); this is thus interpreted as growth zoning. This is in contrast with the diffusive blurring of $\mathrm{Mg}$ and $\mathrm{Mn}$ zoning at a scale of 100-200 $\mu \mathrm{m}$ (Fig. 1 and Online Resource Fig. S2), which is not observed in any of the detectable TE. This indicates that none of the detectable TE, including the transition metals Sc, $\mathrm{V}$ and $\mathrm{Cr}$, display any diffusion equilibration at the conditions recorded by the CLM6 sample ( $\max 600^{\circ} \mathrm{C}$ and cooling over 15-30 My). The garnet core underwent two metamorphic cycles at amphibolite-facies conditions (Variscan and Alpine orogeny, see above), whereas the rim only recorded Alpine metamorphism and remained at $500-600^{\circ} \mathrm{C}$ for $\sim 15$ My (Boston et al. 2017). The duration of the Variscan metamorphism is unconstrained, but expected to be of the same order of magnitude. 
Element diffusion is observed in the granulite-facies MG1 garnet in core and mantle: while the mantle-rim boundary is sharp in both major and trace elements, the TE show compositional zoning in the large garnet core and mantle where $\mathrm{Ca}$ and $\mathrm{Mn}$ are homogenously distributed. The high lateral resolution of the LA-ICP-TOFMS maps allows assessing how sharp the TE zoning is. As for the CLM6 garnet, it is expected that the initial zoning of the major elements in the garnet core matches that of TE such as Y and HREE. In garnet MG1, these slow diffusing elements do not show sharp zoning at the microscale, for example between the core and the mantle (Fig. 10), as instead observed in CLM6 garnet for the same elements. While it cannot be excluded that the gradual zoning in $\mathrm{Y}+\mathrm{HREE}$ in garnet MG1 is a growth feature, this pattern suggests diffusion.

Representative compositional profiles for Y and HREE between garnet core and mantle were extracted from the maps by averaging spots along core-mantle profiles (Fig. 10 and Online Resource Fig. S5-S8). The mass fraction change as a function of distance fits the solution of a diffusion law and permits calculating diffusion coefficients $D$ (in $\mathrm{m}^{2} \mathrm{~s}^{-1}$; expressed in $\log D$ ). The $\log D$ values for each element were obtained by inversion based on single-component diffusion over a time interval of $10 \mathrm{My}$ in a homogeneous medium along a one-dimensional semiinfinite profile (see details in Online Resource). The 10 My period is based on the P-T-time constrained by Hermann and Rubatto (2003) for this sample and represents a minimum estimate of the period of time that the sample remained above $750^{\circ} \mathrm{C}$ after the growth of the garnet mantle.

The extracted values of $\log D$ are between -22.8 and $-23.3 \mathrm{~m}^{2} \mathrm{~s}^{-1}$ for $\mathrm{Y}$ and HREE (Fig. 10 and Online Resource Fig. S7 and S8). Lower diffusion coefficients would be obtained if (i) a longer residence time at these temperatures is used, (ii) the section is not perpendicular to the core/mantle boundary, and (iii) if part of the transitional zoning was due to growth. When compared to literature data calculated at $1 \mathrm{GPa}, 750{ }^{\circ} \mathrm{C}$ and $800{ }^{\circ} \mathrm{C}$ (Fig. 10) our $D$ values show a good match with the diffusion coefficients of Carlson (2012) obtained via numerical simulation on natural data, and with the experimental data of Bloch et al. (2015) for Lu and Dy. The diffusion coefficients for Y obtained in our study are instead 
an order-of-magnitude lower than diffusion coefficients derived from experimental data by Cherniak (2005).

This modelling shows that the gradual zoning between mantle and core of granulite garnet MG1 is reconcilable with diffusion of Y and HREE across 200 $\mu \mathrm{m}$ in $10 \mathrm{My}$ at temperatures of $750-800^{\circ} \mathrm{C}$. An advantage of the mapping technique is that the profiles can be perfectly placed so that they are perpendicular to the compositional interface, and avoid inclusions and heterogeneities that compromise the diffusion modelling.

Our data unfortunately do not allow a comparison of the diffusivity of Lu with that of $\mathrm{Hf}$, or of Sm with Nd, which are mostly below LOD in MG1 garnet, and thus prevents us from making conclusions on relative diffusivities of the elements used for garnet geochronology (Kohn 2009; Bloch et al. 2015). Our data however confirm that Lu can diffuse over hundreds of microns in granulite facies garnet over geological times. This has implications for the interpretation of Lu-Hf garnet ages as they may not record garnet growth, but cooling below a certain $\mathrm{T}$ in granulite-facies rocks.

\section{Garnet growth mechanisms recorded by trace element zoning}

The similarities and differences in the TE zoning patterns observed in the three samples can be related to the different mechanism and conditions of garnet growth. Previous studies have identified different processes that can control TE incorporation and thus zoning in garnet (Pyle and Spear 1999; Otamendi et al. 2002; Skora et al. 2006; Moore et al. 2013; Ague and Axler 2016; George et al. 2018). The TE zoning images obtained can be used to identify which of these processes was dominant during garnet growth at the different conditions.

\section{1) Equilibrium subsolidus growth}

Equilibrium growth with a constant matrix composition and not limited by TE diffusion in the matrix produces simple zoning patterns typical of Rayleigh fractionation (Hollister 1966; Otamendi et al. 2002; Moore et al. 2013). The resulting zoning pattern in garnet is a gradual decrease from core to rim in the mass fractions of TE (bell shape) that are compatible in garnet. This is the dominant zoning type observed for Sc, Y and HREE in the core of the garnet 
grains investigated, and particularly in garnet CLM6 and MG1. The establishment of equilibrium growth in TE in CLM6 and MG1 garnets lends support to the TE partitioning with other phases calculated in previous studies (Hermann and Rubatto 2003; Boston et al. 2017).

\section{2) Peritectic garnet growth}

In sample MG1, a part from the core, an additional zone with high TE content (mantle) is present (Fig. 6). The gradational transition from core to mantle is compatible with diffusional relaxation of a sharp boundary (see above). The mantle is much broader in size than thin annuli observed in garnet grown at lower temperatures (CLM6 and AV garnet, see discussion below). V, Cr, Zr, Y and the M-HREE are enriched in the mantle with respect to the outer core. Based on petrological, geochronological and inclusion evidence, Hermann and Rubatto (2003) related the garnet core to prograde metamorphism mainly at subsolidus conditions and the mantle to peritectic garnet growth during biotite melting. During the growth of the garnet mantle, $\mathrm{V}$ was likely liberated by muscovite and biotite melting (Yang and Rivers 2000), whereas Zr, Y and REE could be derived from dissolution of accessory phases, including xenotime, zircon and monazite. The Zr zoning should be particularly diagnostic for the transition of subsolidus to suprasolidus garnet growth as the solubility of $\mathrm{Zr}$ in the fluid phase increases over at least an order of magnitude from an aqueous fluid to a hydrous melt (Hermann and Rubatto 2009). Another feature of growth zoning in the presence of melt is that TE mass fractions can increase towards the garnet rim as seen in the REE. This is likely related to the increase of REE solubility with increasing temperature in the coexisting melt buffered by monazite (Stepanov et al. 2012) during prograde garnet growth. The embayed shape of the core-mantle boundary in most Y+REE may also indicate that the first melt resorbed a small amount of the core garnet.

Notably, Lu is enriched in this mantle domain, which is volumetrically significant. It implies that in this sample Lu-Hf ages would not preferentially date the core, as argued for most garnet in crustal rocks (e.g. Lapen et al. 2003; Skora et al. 2006), instead Lu-Hf ages in this sample would be intermediate between initial garnet growth in subsolidus and final growth during late anatexis. Lu enrichment 
during melting has a similar effect to Lu enrichment in garnet during intense resorption as proposed by Kelly et al. (2011).

\section{3) Diffusion-limited uptake of TE}

This mechanism produces zoning patterns with a central peak and annular maxima (broad annulus where the TE mass fraction is higher) as modelled by Skora et al. (2006) and Moore et al. (2013). The model predicts a progressive shift in the position of the maximum REE mass fraction from core to rim for heavy to mid-REE (MREE), as the REE are incorporated progressively later with decreasing atomic number, due to the relatively slow diffusivity of the lighter REE. The resulting zoning can have many variations as it depends on relative diffusivities, T and duration of growth (Moore et al. 2013).

Models agree that diffusion-limited uptake during growth is more pronounced at lower $\mathrm{T}$ when the diffusivity is slow, and becomes negligible at high $\mathrm{T}$. By comparing garnet zoning in metapelites from two localities, Moore et al. (2013) put the limit where diffusion-limited supply is dominant between 465 and $550^{\circ} \mathrm{C}$. This feature has been observed in garnet from amphibolite-facies metapelites (Moore et al. 2013; George et al. 2018) and from eclogites (Skora et al. 2006) where prograde garnet growth is documented to a maximum $\mathrm{T}$ between $500-$ $600^{\circ} \mathrm{C}$. Amphibolite-facies garnet CLM6 does not exhibit broad annular maxima for $\mathrm{Y}$ and the REE, but these elements decrease constantly from the inner to the outer core (Fig 4 and 5). The identical shape in Y+REE zoning testifies to the fact that diffusion-limited supply and uptake of REE was not a significant mechanism during the growth of CLM6 garnet.

A diffusion-limited uptake of REE would fit, to some extent, the zoning observed in eclogitic $\mathrm{AV}$ garnet, whose centre/rim ratio mass fractions progressively decrease from Lu to Dy (Fig. 7). According to this mechanism, the core to rim growth in AV garnet would be continuous, which is however hard to reconcile with the very steep increase in Y, Dy, Ho and even Sc at the core-rim boundary. An alternative explanation for this type of zoning would be rim formation following an increase in MREE in the reactive bulk composition, e.g. by breakdown of a MREE-rich mineral (see mechanism 4 below). Therefore, we 
conclude that the garnet core in sample AV shows no diffusion-limited uptake of REE.

Conforming with model predictions (Moore et al. 2013), annular maxima are not observed in granulite-facies MG1 garnet because at high temperature TE diffusion in the matrix is increasingly fast and can keep pace with garnet growth.

\section{4) Trace element supply by the breakdown of major and accessory phases}

The breakdown of major or accessory minerals during garnet growth has been recognized to form sharp annuli in garnet for specific TE such as MREE (controlled by titanite and epidote) or P (controlled by apatite) (Pyle and Spear 1999; Yang and Rivers 2002; Konrad-Schmolke et al. 2008; Gieré et al. 2011; Spandler et al. 2011; Raimondo et al. 2017). Another feature of reactioncontrolled TE availability is the decoupling of equally compatible elements, such as for example a different zoning in $\mathrm{Y}$ vs. $\mathrm{Mn}$, which are hosted in distinct minerals (Konrad-Schmolke et al. 2006).

This type of zoning is prominent in the external part of the core of amphibolitefacies CLM6 garnet, where a few annuli are present in Sc, Y and Yb. In CLM6 the annuli in $\mathrm{Ca}$ and $\mathrm{Y}$ do not match in the inner part, but partly correspond in the outer part of the core. The breakdown of accessory amounts of xenotime (48 wt\% Y, 1.5-4 wt\% Yb; e.g. Pyle and Spear 2000) or allanite (2000-5000 $\mu \mathrm{g} / \mathrm{g} \mathrm{Y}$ and $50-350 \mu \mathrm{g} / \mathrm{g} \mathrm{Yb}$; Boston et al. 2017) could provide significant $\mathrm{Y}$ to form minor annuli in garnet that roughly preserve the same $\mathrm{Y} / \mathrm{Yb}$ ratio $(1500 \mu \mathrm{g} / \mathrm{g} \mathrm{Y}$ and $120 \mu \mathrm{g} / \mathrm{g} \mathrm{Yb}$ ). While xenotime and allanite were not observed in sample CLM6, xenotime has been reported as an included phase in garnet from metapelites in the area (Gieré et al. 2011) and allanite is present in other Campolungo metapelites (Boston et al. 2017). Likewise, Giere et al. (2011) proposed that the $\mathrm{Y}$ and $\mathrm{Yb}$ annuli in similar garnet from this area were produced by the breakdown of allanite.

The oscillatory zoning in the rim of eclogitic garnet $\mathrm{AV}$ could be related to breakdown of accessory minerals, and because the oscillatory pattern is marked in different type of elements ( $\mathrm{Ti}, \mathrm{Cr}, \mathrm{Y}$ and M-HREE) that would require the synchronous breakdown of multiple minerals. The REE patterns of the AV garnet (Fig. 9) display a pronounced increase in MREE from core (zone 1-4) to rim 
(zone 5-7); this enrichment is in agreement with the breakdown of epidote/allanite and/or lawsonite that are a main repository for these elements in blueschist-facies rocks (Spandler et al. 2003). Indeed, Zucali et al. (2004) proposed that epidote and lawsonite were consumed between stage 1 and 2 of garnet growth. A milder enrichment in MREE also exists between zone 1 and 2 in AV garnet and this could correspond to the prograde breakdown of titanite to rutile.

\section{5) Inherited TE from precursor and neighbouring phases}

Overprinting zoning, inherited from the prior distribution of TE in precursor minerals, is predicted to produce small-scale irregular zoning patterns disconnected from major elements. This has been most commonly documented in garnet from amphibolite and eclogite-facies rocks for $\mathrm{Ca}, \mathrm{Cr}$ and $\mathrm{Ti}$ (Spandler et al. 2011; Moore et al. 2013; Angiboust et al. 2014; Raimondo et al. 2017; George et al. 2018).

Zoning reconcilable with this mechanism is observed in granulite-facies MG1 garnet and eclogitic AV garnet. In MG1 garnet, the HREE Er-Lu (Fig. 6) show patchy zoning in the inner core and this could be related to inheritance from precursor phases, by which the prograde and relatively low temperature core grew before trace element equilibration was reached at the mm scale. Another zoning feature comparable to inheritance is the enrichment of $\mathrm{Ti}, \mathrm{Cr}$ and $\mathrm{V}$ in parts of the thin rim of MG1 garnet (Fig. 4) in contact with retrogressed biotite. It is proposed that these elements were acquired from nearby biotite, but the process by which this happens is still unclear. In the AV garnet, the patchy distribution of $\mathrm{V}$ and $\mathrm{Cr}$ (Fig. 7) can also be explained as inherited from previous phases, most likely lawsonite and/or epidote.

\section{6) Fluid related equilibration and replacement}

Mineral replacement is a general term to address the process by which a mineral that comes into contact with a fluid out of equilibrium will tend to be replaced by a new mineral to reduce the free energy of the system (Putnis 2009). This replacement, also called interface coupled dissolution-precipitation (Putnis 2009), can also occur by garnet of a different composition that replaces pre- 
existing garnet (e.g. Ague and Axler 2016). This process necessarily involves fluids and, when replacement is not complete, it commonly produces irregular zoning features, embayments, truncated zoning patterns and may be associated with porosity or hydrofractures. Such a process has been documented for secondary garnet replacing garnet in numerous cases from high-T granulites (Pollok et al. 2008; Ague and Axler 2016) to low-T eclogites (Erambert and Austrheim 1993; Kurz et al. 1998; Zack et al. 2002; Angiboust et al. 2011; Giuntoli et al. 2018) based on major element zoning.

The radial pattern of veinlets that cut across the main zoning in $\mathrm{Mg}$ and $\mathrm{Mn}$ in eclogitic garnet $\mathrm{AV}$ is interpreted as replacement (Fig. 7). The high lateral resolution of the LA-ICP-TOFMS TE maps allows resolving these thin radial features. Only the divalent cations Co and $\mathrm{Zn}$, which have the same geochemical affinities as $\mathrm{Mn}$ and $\mathrm{Mg}$, show the replacement features. None of the other detected TE are affected by garnet replacement. In the areas of intense replacement there is no significant correlation between $\mathrm{Mg}$ and other trace elements (see an example for Sc, V, Y and Er in Online Resource Fig. S4). This suggests that the veinlets do not represent a crack-seal mechanism in garnet as proposed by other studies that only looked at major elements (Angiboust et al. 2011; Giuntoli et al. 2018), but are rather related to a selective replacement that affected only some elements. This does not exclude that a micro-crack has acted as a fast fluid pathway in the centre of the veinlets, but replacement is the mechanism that controls garnet re-equilibration in this sample. The replacement can be partial and is likely controlled by the local bonding environment in the garnet, element mobility in the fluid and/or chemical potential gradients, by which the TE were not compatible in any of the nearby minerals forming at the time of garnet replacement.

\section{Conclusions}

We have demonstrated that LA-ICP-TOFMS can produce accurate and detailed images of TE zoning in garnet at a lateral resolution of $5 \mu \mathrm{m}$ and with limits of detection suitable for mapping a wide range of elements at mass fractions down to sub $\mu \mathrm{g} / \mathrm{g}$ levels. Mapping of TE in garnet grains that formed in different 
conditions from eclogite $\left(500-600^{\circ} \mathrm{C}\right)$ to amphibolite $\left(600^{\circ} \mathrm{C}\right)$ to granulite facies $\left(850^{\circ} \mathrm{C}\right)$ provides insight into their growth mechanism and the distribution of TE during metamorphism in the presence of fluid and melt.

The method can generate TE maps that provide quantitative data to establish diffusivities of elements in garnet. The gradual zoning between mantle and core of the granulite-facies garnet is reconcilable with diffusion $Y$ and HREE over $\sim 200 \mu \mathrm{m}$ in $10 \mathrm{My}$ at temperatures of $750-800^{\circ} \mathrm{C}$.

TE distribution in metapelite garnet grown at upper amphibolite to granulite facies is mainly controlled by an equilibrium Rayleigh fractionation process.

Peritectic garnet growth in the presence of melt is recognised in the granulitefacies sample, and marked by an increase in $\mathrm{V}, \mathrm{Cr}, \mathrm{Zr}, \mathrm{Y}$ and the M-HREE. The redistribution for these elements in the melt is related to the melting of biotite $(\mathrm{V}$ and $\mathrm{Cr}$ ), and the solubility of accessory minerals zircon and monazite.

Annuli or sharp enrichments in TE due to the breakdown of TE-rich minerals are confirmed to be typical of amphibolite-facies garnet, and also present in eclogitic garnet. The correlation between different TE can be used to speculate about the TE-rich phase that is breaking down and helps to correlate garnet growth with metamorphic reactions and accessory phase stability. Diffusion-limited uptake is not a dominant mechanism in any of the investigated garnet grains and is not observed even in the relatively low T eclogite garnet.

Overprinting zoning, inherited from precursor minerals, is identified in the core of granulite-facies garnet for HREE and in the eclogite-facies garnet for $\mathrm{Cr}$ and $\mathrm{V}$, possibly in relation to epidote. In the granulite-facies metapelite, $\mathrm{Ti}, \mathrm{Cr}$ and $\mathrm{V}$ can have enriched mass fraction when garnet grows in contact with (or in place of) high-T biotite.

Fluid-induced, secondary garnet replacement that affected the major elements in the eclogite-facies sample did not perturb the TE, with the exclusion of $\mathrm{Zn}$ and Co, divalent cations that substitute for $\mathrm{Mg}$ and $\mathrm{Fe}$. This is in line with the low solubility of TE in aqueous fluids. The undisturbed TE distribution in the secondary replacement also indicates that this rather common garnet zoning in eclogites does not necessarily proceed by a crack-seal process. 


\section{References}

Ague JJ, Axler JA (2016) Interface coupled dissolution-reprecipitation in garnet from subducted granulites and ultrahigh-pressure rocks revealed by phosphorous, sodium, and titanium zonation. Am Mineral 101:1696-1699

Anczkiewicz R, Chakraborty S, Dasgupta S, Mukhopadhyay D, Kołtonik K (2014) Timing, duration and inversion of prograde Barrovian metamorphism constrained by high resolution Lu-Hf garnet dating: A case study from the Sikkim Himalaya, NE India. Earth Planet Sci Lett 407:70-81

Anczkiewicz R, Szczepanski J, Mazur S, Storey C, Crowley Q, Villa IM, Thirlwall MF, Jeffries TE (2007) Lu-Hf geochronology and trace element distribution in garnet: Implications for uplift and exhumation of ultra-high pressure granulites in the Sudetes, SW Poland. Lithos 95:363-380

Angiboust S, Agard P, Raimbourg H, Yamato P, Huet B (2011) Subduction interface processes recorded by eclogite-facies shear zones (Monviso, W. Alps). Lithos 127:222-238

Angiboust S, Pettke T, De Hoog JCM, Caron B, Oncken 0 (2014) Channelized fluid flow and eclogite-facies metasomatism along the subduction shear zone. J Petrol 55:883916

Bloch E, Ganguly J, Hervig R, Cheng W (2015) 176 Lu-176 Hf geochronology of garnet I: experimental determination of the diffusion kinetics of Lu 3+ and Hf 4+ in garnet, closure temperatures and geochronological implications. Contrib Mineral Petrol 169:12

Boston K, Rubatto D, Hermann J, Engi M, Amelin Y (2017) Geochronology of accessory allanite and monazite in the Barrovian metamorphic sequence of the Central Alps, Switzerland Lithos 286-287:502-518

Burger M, Hendriks L, Kaeslin J, Gundlach-Graham A, Hattendorf B, Günther D (2019) Characterization of inductively coupled plasma time-of-flight mass spectrometry in combination with collision/reaction cell technology - insights from highly timeresolved measurements Journal of Analytical Atomic Spectrometry 34:135-146

Burger M, Schwarz G, Gundlach-Graham A, Käser D, Hattendorf B, Günther D (2017) Capabilities of laser ablation inductively coupled plasma time-of-flight mass spectrometry. Journal of Analytical Atomic Spectrometry 32:1946-1959

Bussweiler Y, Borovinskaya 0, Tanner M (2017) Laser Ablation and inductively coupled plasma-time-of-flight mass spectrometry - A powerful combination for high-speed multielemental imaging on the micrometer scale. Spectroscopy 32:20

Bussweiler Y, Gervasoni F, Rittner M, Berndt J, Klemme S (2019) Trace element mapping of high-pressure, high-temperature experimental samples with laser ablation ICP time-of-flight mass spectrometry-Illuminating melt-rock reactions in the lithospheric mantle. Lithos:105282

Caddick MJ, Konopásek J, Thompson AB (2010) Preservation of garnet growth zoning and the duration of prograde metamorphism. J Petrol 51:2327-2347

Carlson WD (2012) Rates and mechanism of Y, REE, and Cr diffusion in garnet. Am Mineral 97:1598-1618

Chakraborty S (2006) Diffusion modeling as a tool for constraining timescales of evolution of metamorphic rocks. Mineral Petrol 1-22

Cherniak D (2005) Yb and Y diffusion in grossular garnet Geochimica et Cosmochimica Acta Supplement 69:405

Cherniak DJ (2005) Yb and Y diffusion in grossular garnet. Geochimica et Cosmochimica Acta, Supplement 69:405

Delleani F, Rebay G, Zucali M, Tiepolo M, Spalla MI (2018) Insight on Variscan geodynamics from the structural and geochemical characterization of a Devonian- 
Carboniferous gabbro from the Austroalpine domain (Western Alps) Ofioliti 43:2339

Erambert M, Austrheim H (1993) The effect of fluid and deformation on zoning and inclusion patterns in poly-metamorphic garnets. Contrib Mineral Petrol 115:204-214

Ferry JM, Watson EB (2007) New thermodynamic models and revised calibrations for the Ti-in-zircon and Zr-in-rutile thermometers Contrib Mineral Petrol 154:429-437

George FR, Gaidies F, Boucher B (2018) Population-wide garnet growth zoning revealed by LA-ICP-MS mapping: implications for trace element equilibration and synkinematic deformation during crystallisation. Contrib Mineral Petrol 173:74

Gieré R, Rumble D, Günther D, Connolly J, Caddick MJ (2011) Correlation of Growth and Breakdown of Major and Accessory Minerals in Metapelites from Campolungo, Central Alps. J Petrol 52:2293-2334

Giuntoli F, Lanari P, Engi M (2018) Deeply subducted continental fragments - Part 1: Fracturing, dissolution-precipitation, and diffusion processes recorded by garnet textures of the central Sesia Zone (western Italian Alps). Solid Earth 9:167-189

Green TH, Blundy JD, Adam J, Yaxley GM (2000) SIMS determination of trace element partition coefficients between garnet, clinopyroxene and hydrous basaltic liquids at 2-7.5 GPa and $1080-1200^{\circ} \mathrm{C}$. Lithos 53:165-187

Guilmette C, Smit MA, van Hinsbergen DJJ, Gürer D, Corfu F, Charette B, Maffione M, Rabeau O, Savard D (2018) Forced subduction initiation recorded in the sole and crust of the Semail Ophiolite of Oman. Nature Geoscience 11:688-695

Gundlach-Graham A, Burger M, Allner S, Schwarz G, Wang HAO, Gyr L, Grolimund D, Hattendorf B, Günther D (2015) High-Speed, High-Resolution, Multielemental Laser Ablation-Inductively Coupled Plasma-Time-of-Flight Mass Spectrometry Imaging: Part I. Instrumentation and Two-Dimensional Imaging of Geological Samples Anlytical Chemistry 87:8250-8258

Gundlach - Graham A, Garofalo PS, Schwarz G, Redi D, Günther D (2018) High resolution, Quantitative Element Imaging of an Upper Crust, Low - angle Cataclasite (Zuccale Fault, Northern Apennines) by Laser Ablation ICP Time - of - Flight Mass Spectrometry. Geostandards and Geoanalytical Research 42:559-574

Hermann J, Müntener O, Trommsdorff V, Hansmann W, Piccardo GB (1997) Fossil crust to mantle transition, Val Malenco (Italian Alps). J Geophys Res 102:20'123-120'132

Hermann J, Rubatto D (2003) Relating zircon and monazite domains to garnet growth zones: age and duration of granulite facies metamorphism in the Val Malenco lower crust. J Metamorphic Geol 21:833-852

Hermann J, Rubatto D (2009) Accessory phase control on the trace element signature of sediment melts in subduction zones. Chem Geol 265:512-526

Hickmott DD, Shimizu N, Spear FS, Selverstone J (1987) Trace-element zoning in a metamorphic garnet. Geology 15:573-576

Higashino F, Rubatto D, Kawakami T, Bouvier A-S, Baumgartner LP (2019) Oxygen isotope speedometry in granulite facies garnet recording fluid/melt-rock interaction (Sør Rondane Mountains, East Antarctica). J Metamorphic Geol 37:1037-1048

Hirsch DM, Prior DJ, Carlson WD (2003) An overgrowth model to explain multiple, dispersed high-Mn regions in the cores of garnet porphyroblasts. Am Mineral 88:131141

Hollister LS (1966) Garnet zoning: an interpretation based on the Rayleigh fractionation model. Science 154:1647-1651

Horn I, Guillong M, Günther D (2001) Wavelength dependant ablation rates for metals and silicate glasses using homogenized laser beam profiles-implications for LA-ICPMS. Applied Surface Science 182:91-102

Hyppolito T, Cambeses A, Angiboust S, Raimondo T, García-Casco A, Juliani C (2019) Rehydration of eclogites and garnet-replacement processes during exhumation in the amphibolite facies. Geological Society, London, Special Publications 478:217-239 
Jollands MC, Hanger BJ, Yaxley GM, Hermann J, Kilburn MR (2018) Timescales between mantle metasomatism and kimberlite ascent indicated by diffusion profiles in garnet crystals from peridotite xenoliths. Earth Planet Sci Lett 481:143-153

Kelly ED, Carlson WD, Connelly JN (2011) Implications of garnet resorption for the LuHf garnet geochronometer: an example from the contact aureole of the Makhavinekh Lake Pluton, Labrador. J Metamorphic Geol 29:901-916

Kohn MJ (2009) Models of garnet differential geochronology. Geochim Cosmochim Acta 73:170-182

Konrad-Schmolke M, Babist J, Handy MR, O'Brien PJ (2006) The Physico-Chemical Properties of a Subducted Slab from Garnet Zonation Patterns (Sesia Zone, Western Alps). J Petrol 47:2123-2148

Konrad-Schmolke M, Zack T, O'Brien PJ, Jacob DE (2008) Combined thermodynamic and rare earth element modelling of garnet growth during subduction: Examples from ultrahigh-pressure eclogite of the Western Gneiss Region, Norway. Earth Planet Sci Lett 272:488-498

Kurz W, Neubauer F, Dachs E (1998) Eclogite meso- and microfabrics: implications for the burial and exhumation history of eclogites in the Tauern Window (Eastern Alps) from P-T-d paths. Tectonophysics 285:183-209

Lanari P, Engi M (2017) Loal bulk compositional effects on metamorphic mineral assemblages. Reviews in Mineralogy and Geochemistry 83:55-102

Lanari P, Piccoli F (2019) New horizons in quantitative compositional mapping analytical conditions and data reduction using XMAPTOOLS. Institute of Physics Conference Series: Materials Science and Engineering, in press

Lanari P, Vho A, Bovay T, Airaghi L, Centrella S (2019) Quantitative compositional mapping of mineral phases by electron probe micro-analyser. In: Ferrero S, Lanari P, Goncalves P, Grosch EG (eds) Metamorphic Geology: Microscale to Mountain Belts vol 478. Geological Society, Special Publications, London, pp 39-63

Lanari P, Vidal O, De Andrade V, Dubacq B, Lewin E, Grosch EG, Schwartz S (2014) XMapTools: A MATLAB(C)-based program for electron microprobe X-ray image processing and geothermobarometry. Computers \& Geosciences 62:227-240

Lapen TJ, Johnson CM, Baumgartner LP, Mahlen NJ, Beard BL, Amato JM (2003) Burial rates during prograde metamorphism of an ultra-high-pressure terrane: an example from Lago di Cignana, western Alps, Italy. Earth Planet Sci Lett 215:57-72

Liu Y, Hu Z, Gao S, Günther D, Xu J, Gao C, Chen H (2008) In situ analysis of major and trace elements of anhydrous minerals by LA-ICP-MS without applying an internal standard. Chem Geol 257:34-43

Moore SJ, Carlson WD, Hesse MA (2013) Origins of yttrium and rare earth element distributions in metamorphic garnet. J Metamorphic Geol 31:663-689

Müntener 0, Hermann J, Trommsdorff V (2000) Cooling history and exhumation of lower crustal granulites and upper mantle (Malenco, Eastern Central Alps). J Petrol 41:175-200

Otamendi JE, de la Rosa JD, Patiño Douce AE, Castro A (2002) Rayleigh fractionation of heavy rare earths and yttrium during metamorphic garnet growth. Geology 30:159162

Pollok K, Lloyd GE, Austrheim H, Putnis A (2008) Complex replacement patterns in garnets from Bergen Arcs eclogites: A combined EBSD and analytical TEM study. Geochemistry 68:177-191

Putnis A (2009) Mineral Replacement Reactions. Reviews in Mineralogy and Geochemistry 70:87-124

Pyle JM, Spear FS (1999) Yttrium zoning in garnet: Coupling of major and accessory phases during metamorphic reactions. Geological Materials Research 1:1-49

Pyle JM, Spear FS (2000) An empirical garnet (YAG) - xenotime thermometer. Contrib Mineral Petrol 138:51-58 
Raimondo T, Payne J, Wade B, Lanari P, Clark C, Hand M (2017) Trace element mapping by LA-ICP-MS: assessing geochemical mobility in garnet. Contrib Mineral Petrol 172:17

Rubatto D (2002) Zircon trace element geochemistry: distribution coefficients and the link between U-Pb ages and metamorphism. Chem Geol 184:123-138

Rubatto D, Gebauer D, Compagnoni R (1999) Dating of eclogite-facies zircons: the age of Alpine metamorphism in the Sesia-Lanzo Zone (Western Alps). Earth Planet Sci Lett 167:141-158

Rubatto D, Hermann J (2007) Experimental zircon/melt and zircon/garnet trace element partitioning and implications for the geochronology of crustal rocks. Chem Geol 241:62-87

Rubatto D, Regis D, Hermann J, Boston K, Engi M, Beltrando M, McAlpine SRB (2011) YoYo subduction recorded by accessory minerals in the Sesia Zone, Western Alps. Nature Geoscience 4:338-342

Skora S, Baumgartner LP, Mahlen NJ, Johnson CM, Pilet S, Hellebrand E (2006) Diffusionlimited REE uptake by eclogite garnets and its consequences for $\mathrm{Lu}-\mathrm{Hf}$ and $\mathrm{Sm}-\mathrm{Nd}$ geochronology. Contrib Mineral Petrol 152:703-720

Spandler C, Hermann J, Arculus R, Mavrogenes J (2003) Redistribution of trace elements during prograde metamorphism from lawsonite blueschist to eclogite facies; implications for deep subduction-zone processes. Contrib Mineral Petrol 146:205222

Spandler C, Pettke T, Rubatto D (2011) Internal and external fluid sources for eclogitefacies veins in the Monviso meta-ophiolite, Western Alps: Implications for fluid flow in subduction zones. J Petrol 52:1207-1236

Spear FS (1993) Metamorphic phase equilibria and pressure-temperature-time paths. Mineralogical Society of America, Washington D.C.

Spear FS, Kohn MJ (1996) Trace element zoning in garnet as a monitor of crustal melting. Geology 24:1099-1102

Stepanov AS, Hermann J, Rubatto D, Rapp RP (2012) Experimental study of monazite/melt partitioning with implications for the REE, Th and U geochemistry of crustal rocks. Chem Geol 300-301:200-220

Taylor RJM, Clark C, Harley SL, Kylander-Clark ARC, Hacker BR, Kinny PD (2017) Interpreting granulite facies events through rare earth element partitioning arrays. J Metamorphic Geol 35:759-775

Taylor RJM, Harley SL, Hinton RW, Elphick S, Clark C, Kelly NM (2014) Experimental determination of REE partition coefficients between zircon, garnet and melt: A key to understanding high-T crustal processes. J Metamorphic Geol

Todd CS, Engi M (1997) Metamorphic field gradients in the Central Alps. J Metamorphic Geol 15:513-530

Ubide T, Caulfield J, Brandt C, Bussweiler Y, Mollo S, Di Stefano F, Nazzari M, Scarlato P (2019) Deep magma storage revealed by multi-method elemental mapping of clinopyroxene megacrysts at Stromboli volcano. Frontiers in Earth Science 7:239

Ulrich T, Kamber BS, Jugo PJ, Tinkham DK (2009) Imaging elementdistribution patterns in minerals by Laser Ablation-Inductively Coupled Plasma-Mass Spectrometry (LAICP-MS). Can Mineral:1001-1012

van Westrenen W, Draper DS (2007) Quantifying garnet-melt trace element partitioning using lattice-strain theory: New crystal-chemical and thermodynamic constraints. Contrib Mineral Petrol 154:717-730

Vho A (2020) Fluid pathways in the subducting crust: insights from oxygen isotope records in metamorphic minerals, $\mathrm{PhD}$ thesis, Universität Bern, Bern

Wang HAO, Grolimund D, Giesen C, Borca CN, Shaw-Stewart JRH, Bodenmiller B, Günther D (2013) Fast Chemical Imaging at High Spatial Resolution by Laser Ablation Inductively Coupled Plasma Mass Spectrometry. Analytical Chemistry 85:1010710116 
Woodhead JD, Hellstrom J, Hergt JM, Greig A, Maas R (2007) Isotopic and Elemental Imaging of Geological Materials by Laser Ablation Inductively Coupled Plasma-Mass Spectrometry. Geostandards and Geoanalytical Research 31:331-343

Yang P, Rivers T (2000) Trace element partitioning between coexisting biotite and muscovite from metamorphic rocks, Western Labrador: Structural, compositional and thermal controls. Geochim Cosmochim Acta 64:1451-1472

Yang P, Rivers T (2002) The origin of $\mathrm{Mn}$ and $\mathrm{Y}$ annuli in garnet and the thermal dependence of $\mathrm{P}$ in garnet and $\mathrm{Y}$ in apatite in calc-pelite and pelite, Gagnon terrane, western Labrador. Geological Materials Research 4:1-35

Zack T, Foley SF, Rivers T (2002) Equilibrium and Disequilibrium Trace Element Partitioning in Hydrous Eclogites (Trescolmen, Central Alps). J Petrol 43:1947-1974

Zucali M, Spalla MI (2011) Prograde lawsonite during the flow of continental crust in the Alpine subduction: Strain vs. metamorphism partitioning, a field-analysis approach to infer tectonometamorphic evolutions (Sesia-Lanzo Zone, Western Italian Alps) J Struct Geol 33:381-398

Zucali M, Spalla MI, Gosso G, Racchetti S, Zulbati F (2004) Prograde Lws-Ky transition during subduction of the Alpine continental crust of the Sesia-Lanzo Zone: the Ivozio Complex Journal of Virtual Explorer 16:1-21 


\section{Figures}
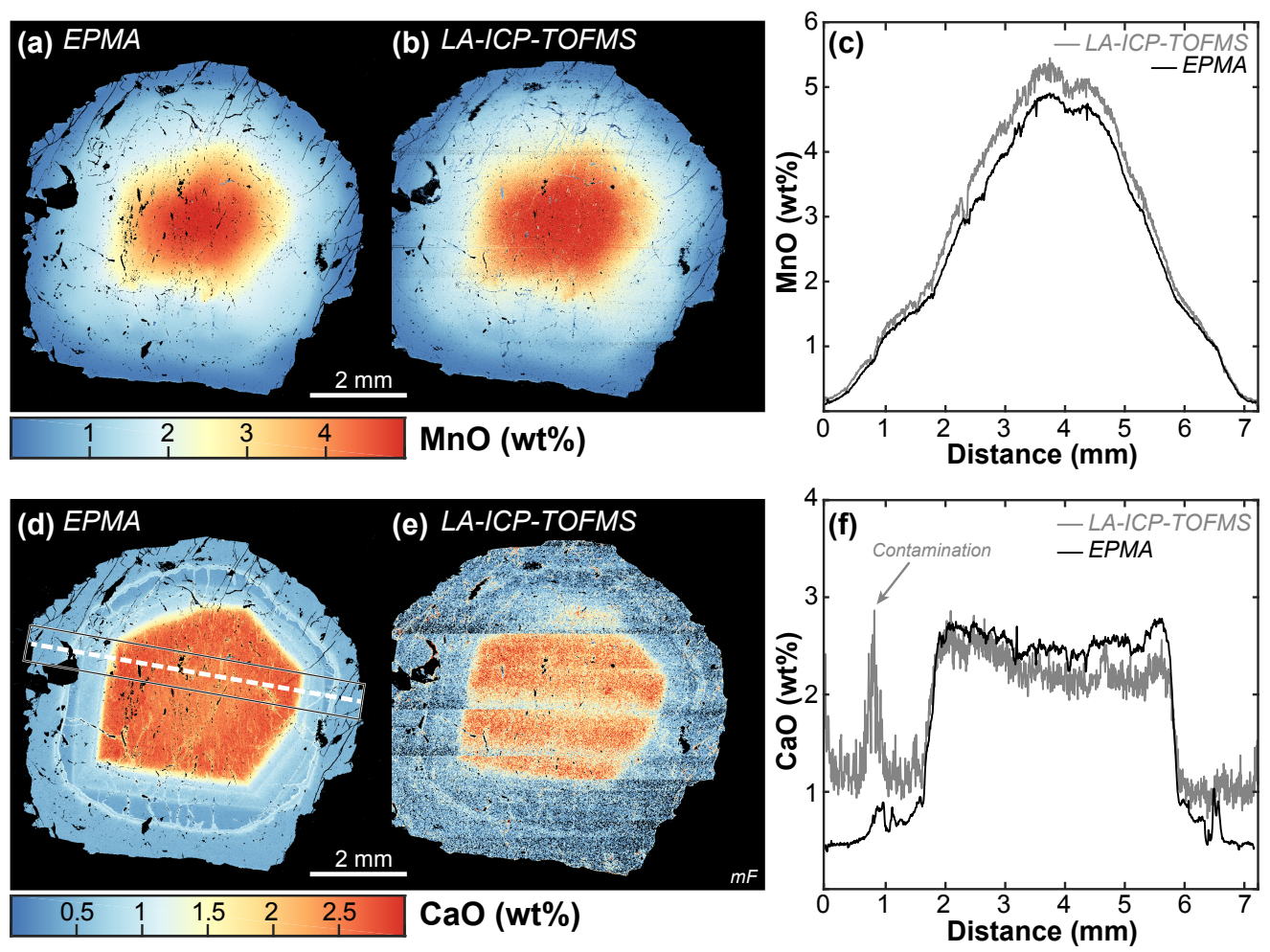

Fig. 1 Comparison between LA-ICP-TOFMS and EPMA zoning in amphibolitefacies sample CLM6 for $\mathrm{MnO}(\mathrm{a}-\mathrm{c}$ ) and $\mathrm{CaO}$ (d-f) both as images and profiles (c and $\mathrm{f}$ ) along the line marked in (d). The slight difference in the $\mathrm{MnO}$ and $\mathrm{CaO}$ mass fractions along the profile is due to the different lateral resolution of the two methods. The horizontal parallel bands in the CaO LA-ICP-TOFMS map are an analytical artefact due to tilting of the thin section that caused the laser to become slightly de-focused during analysis. 


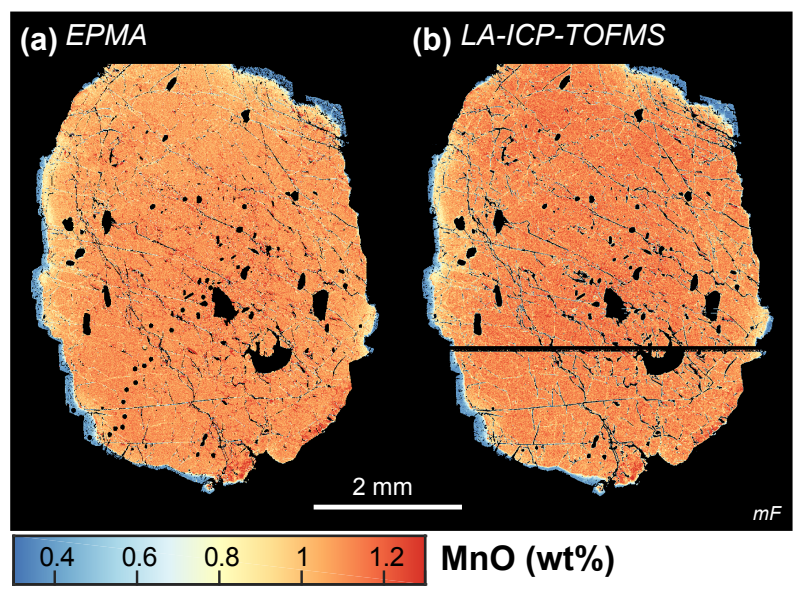

(c)
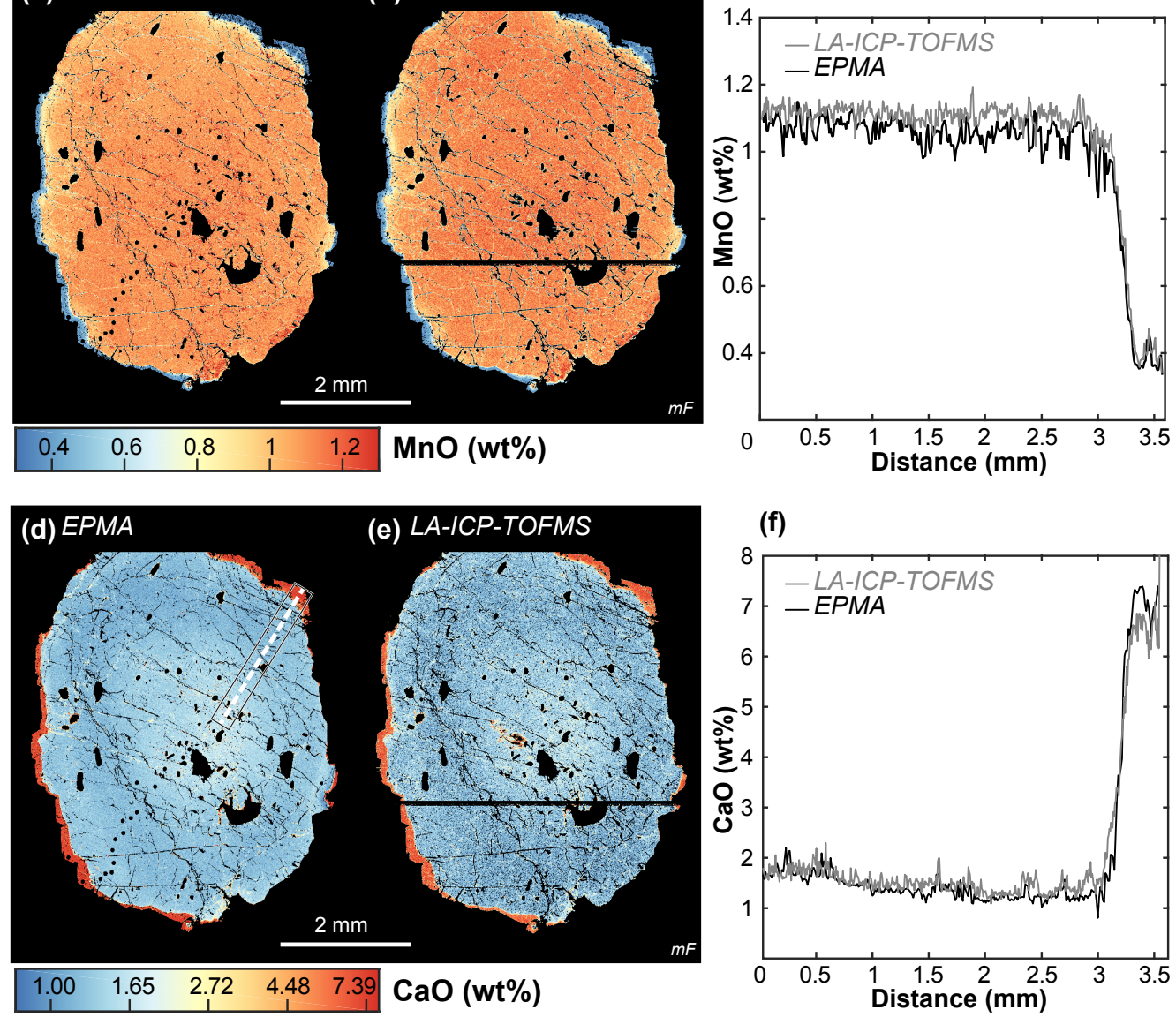

Fig. 2 Comparison between LA-ICP-TOFMS and EPMA zoning in granulite-facies sample MG1 for $\mathrm{MnO}(\mathrm{a}-\mathrm{c}$ ) and $\mathrm{CaO}$ (d-f) both as images and profiles (c and f) along the trace marked in (d).The slight difference in the $\mathrm{MnO}$ and $\mathrm{CaO}$ mass fractions along the profile is due to the different lateral resolution of the two methods. The black line at $2 / 3$ of the garnet height in image (b) and (e) is due to an accidental interruption of the He gas flow. The black circles in the bottom-left quadrant of image (d) are LA-ICPMS spot analyses. 

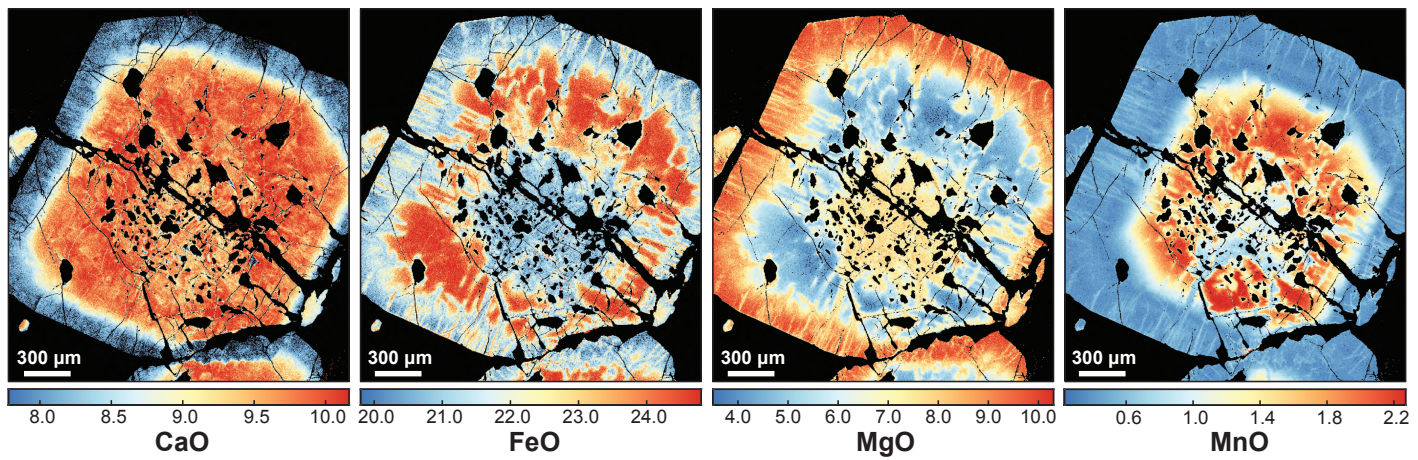

Fig 3 EPMA map of major elements in a garnet grain from eclogitic sample AV; the grain is not the same analysed by LA-ICP-TOFMS, but a nearby one with comparable zoning.

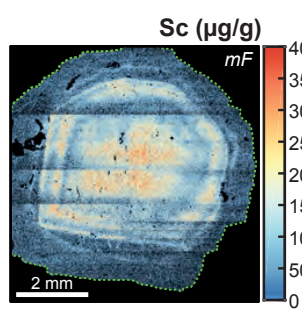

Eu $(\mu \mathrm{g} / \mathrm{g})$

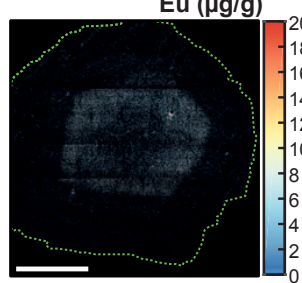

Ho $(\mu \mathrm{g} / \mathrm{g})$

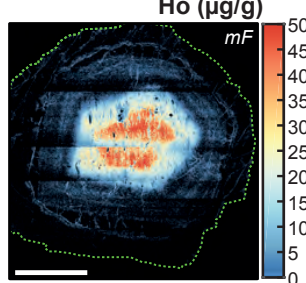

$\mathrm{P}(\mu \mathrm{g} / \mathrm{g})$

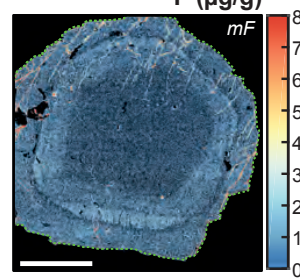

$\mathrm{Gd}(\mu \mathrm{g} / \mathrm{g})$

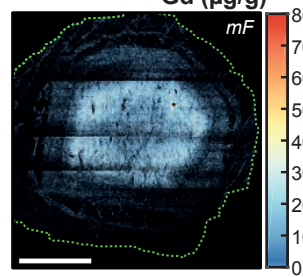

$\mathrm{Tm}(\mu \mathrm{g} / \mathrm{g})$

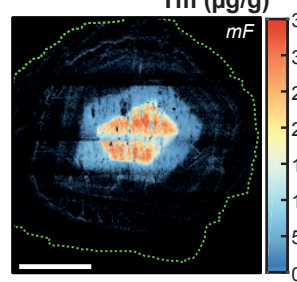

$\mathrm{Y}(\mu \mathrm{g} / \mathrm{g})$

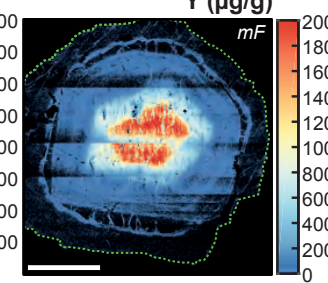

$\mathrm{Tb}(\mu \mathrm{g} / \mathrm{g})$

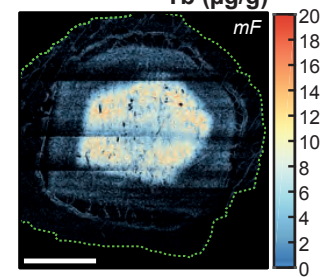

$\mathrm{Yb}(\mu \mathrm{g} / \mathrm{g})$

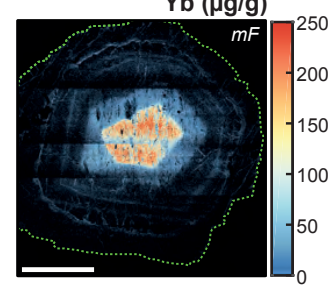

$\mathrm{Ce}(\mu \mathrm{g} / \mathrm{g})$ *

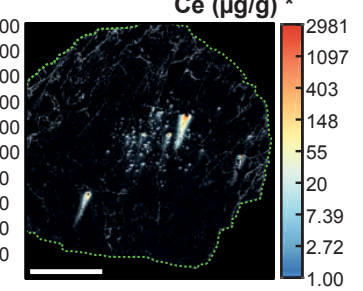

Dy $(\mu \mathrm{g} / \mathrm{g})$

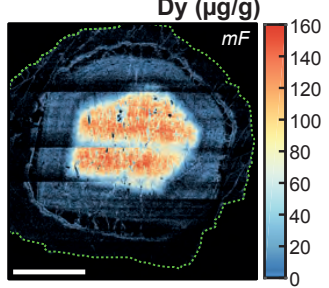

$\mathrm{Lu}(\mu \mathrm{g} / \mathrm{g})$

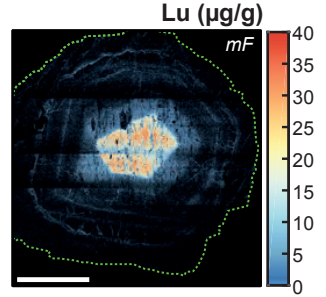

Fig. 4 LA-ICP-TOFMS element maps for amphibolite-facies garnet CLM6 for selected elements. The horizontal parallel bands are an analytical artefact due to tilting of the thin section that caused the laser to become slightly de-focused during analysis. Note that the Ce mass fraction is displayed in a logarithmic scale $\left.{ }^{*}\right)$. Elements for which a median filter has been applied are marked with " $m F$ ". For the median filtering, each pixel was recalculated as the median value in the 2-by-2 neighborhood around the corresponding pixel. 


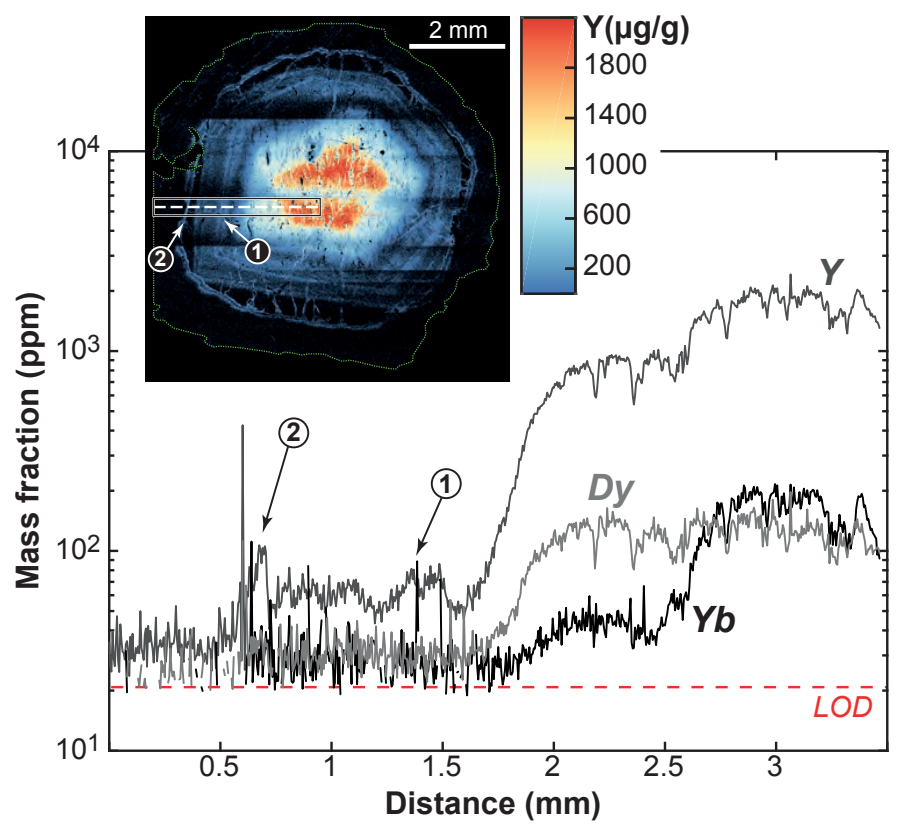

Fig. 5 Mass fraction profile for $\mathrm{Y}$, Dy and Yb from rim to core of amphibolitefacies garnet CLM6 along the trace marked in the map. Note the good correspondence of the three elements: all three elements have the same rise at 1.6-2.0 $\mathrm{mm}$, and $\mathrm{Y}$ and $\mathrm{Yb}$ mark another zone at $2.5 \mathrm{~mm}$. The dotted red line represents the LOD. 

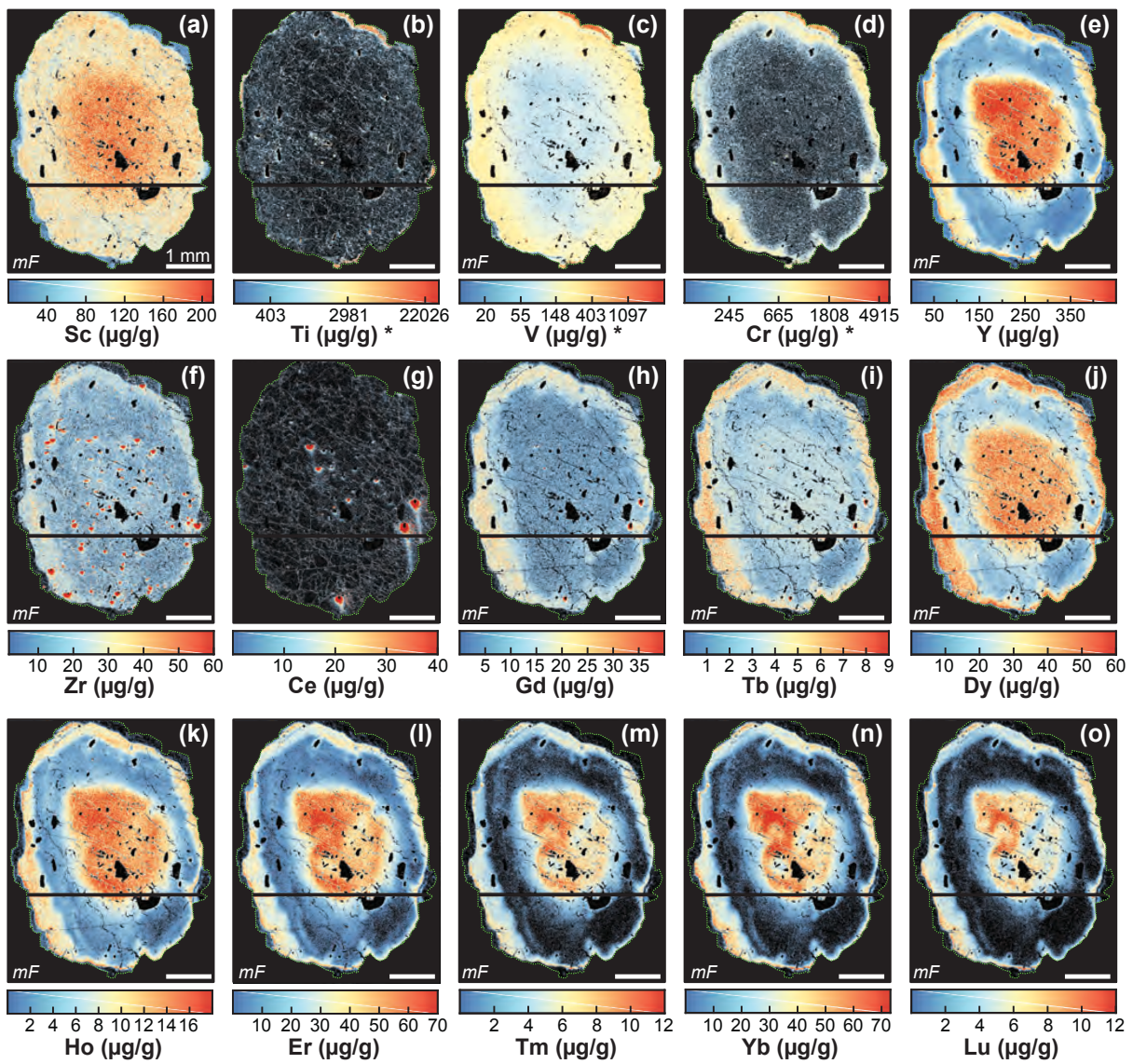

Fig. 6 LA-ICP-TOFMS element maps for granulite-facies garnet MG1 for selected elements. The black line at $2 / 3$ of the garnet height is due to an accidental interruption of the $\mathrm{He}$ gas flow. Ti and $\mathrm{V}$ mass fraction are displayed in a logarithmic scale $(*)$. Maps for which a median filter has been applied are marked with " $m F$ ". For the median filtering, each pixel was recalculated as the median value in the 2-by-2 neighborhood around the corresponding pixel. 

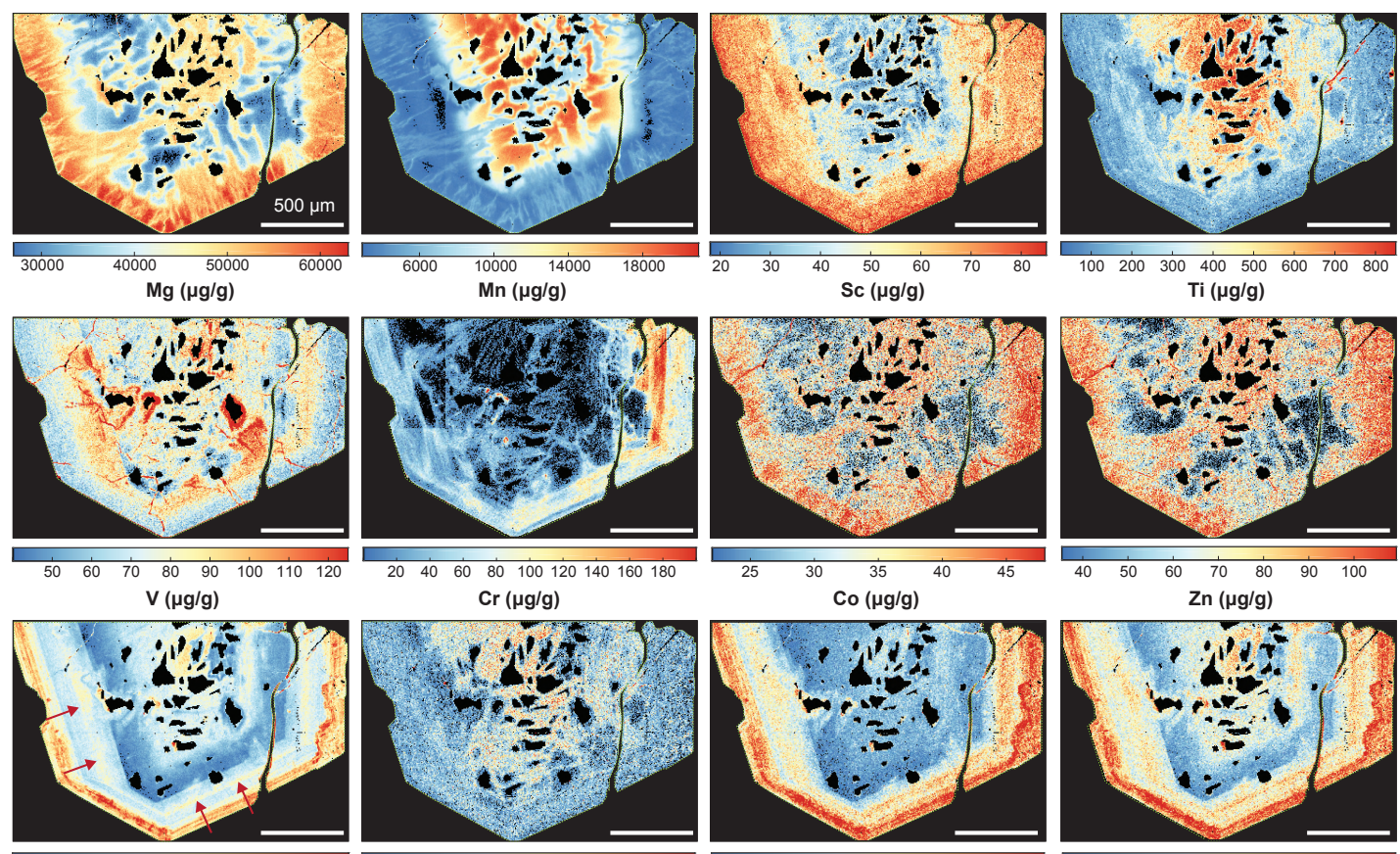

$\operatorname{Cr}(\mu \mathrm{g} / \mathrm{g})$
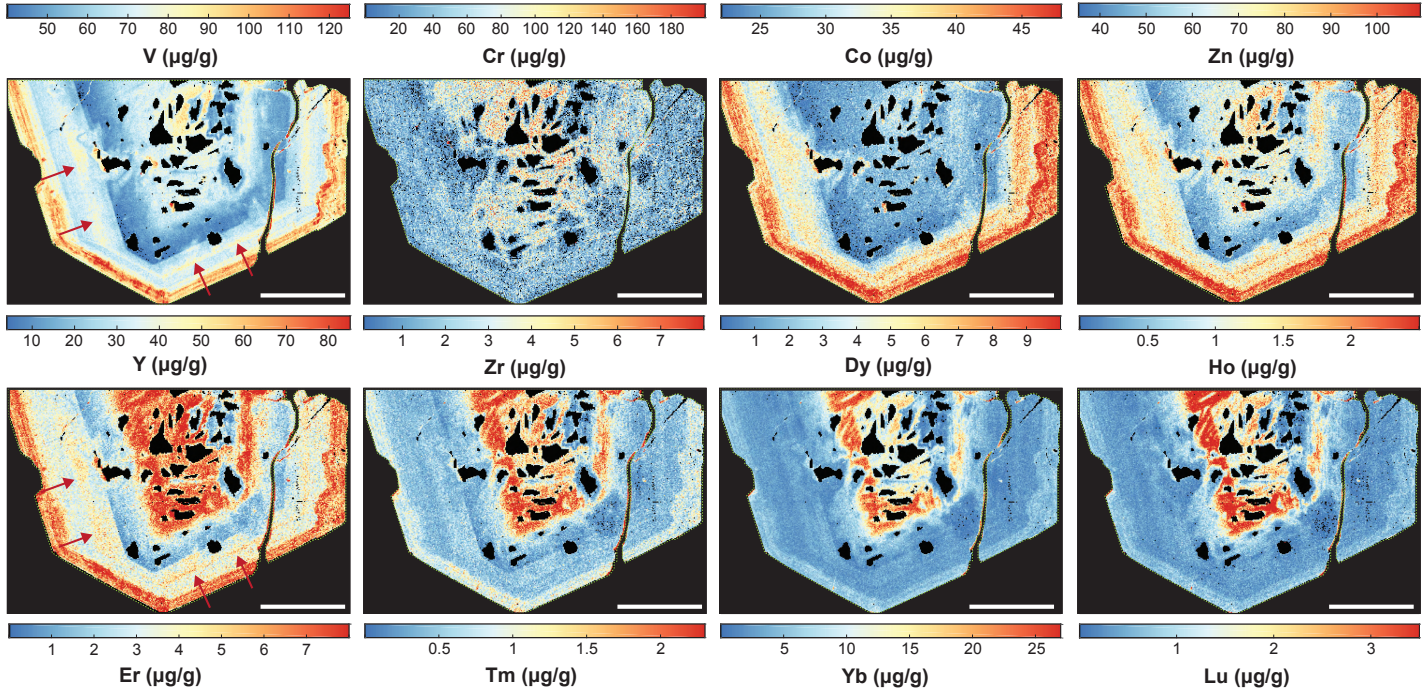

Fig. 7 LA-ICP-TOFMS element maps for eclogitic garnet AV for selected elements. The red arrows in the $\mathrm{Y}$ and Er maps indicate the annulus. See discussion in text.
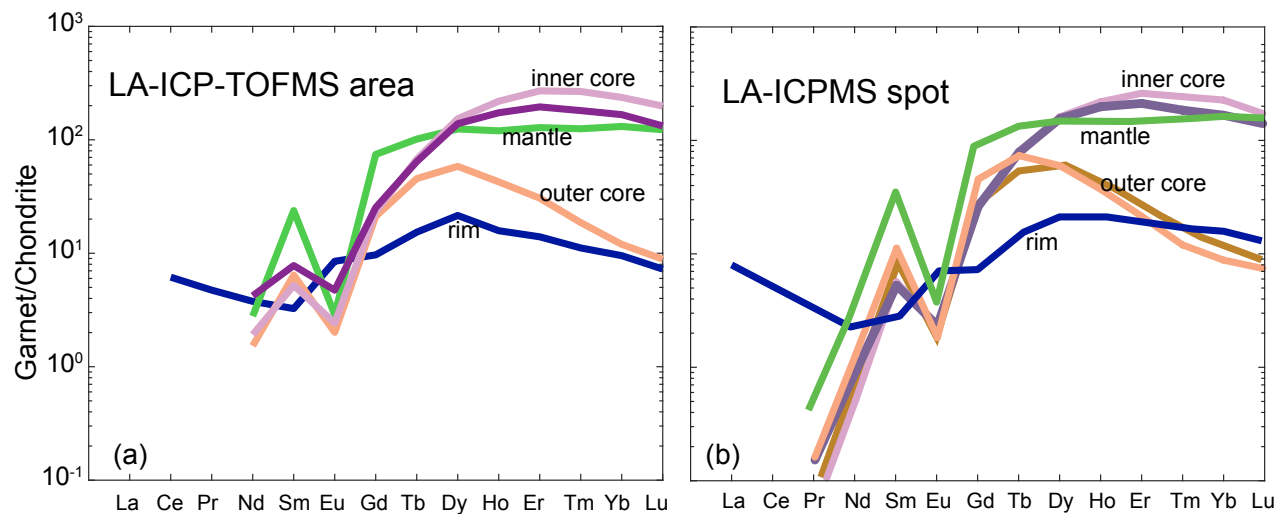

Fig. 8 Chondrite normalized REE patterns for different domains of granulitefacies garnet MG1 obtained using different instrumentation and setups. (a) REE patterns obtained sampling an area of $\sim 50-600$ pixels $\left(\sim 200-2400 \mu \mathrm{m}^{3}\right.$ sample volume) in the LA-ICP-TOFMS maps using the software XMapTools. (b) REE patterns obtained by routine LA-ICPMS spot analysis with a $60 \mu \mathrm{m}$ diameter and $\sim 20 \mu \mathrm{m}$ deep $\left(\sim 56000 \mu \mathrm{m}^{3}\right.$; data in Online Resource Table S2). See text for discussion. 


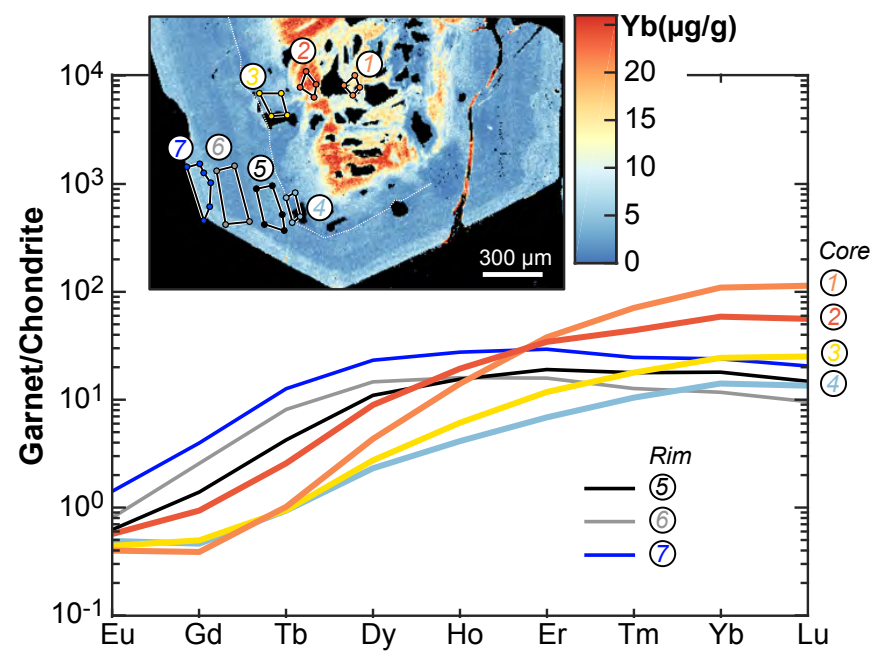

Fig. 9 Chondrite normalized REE patterns for different domains of eclogitic garnet AV obtained by sampling the marked area in the LA-ICP-TOFMS maps shown in the inset using the software XMapTools. 

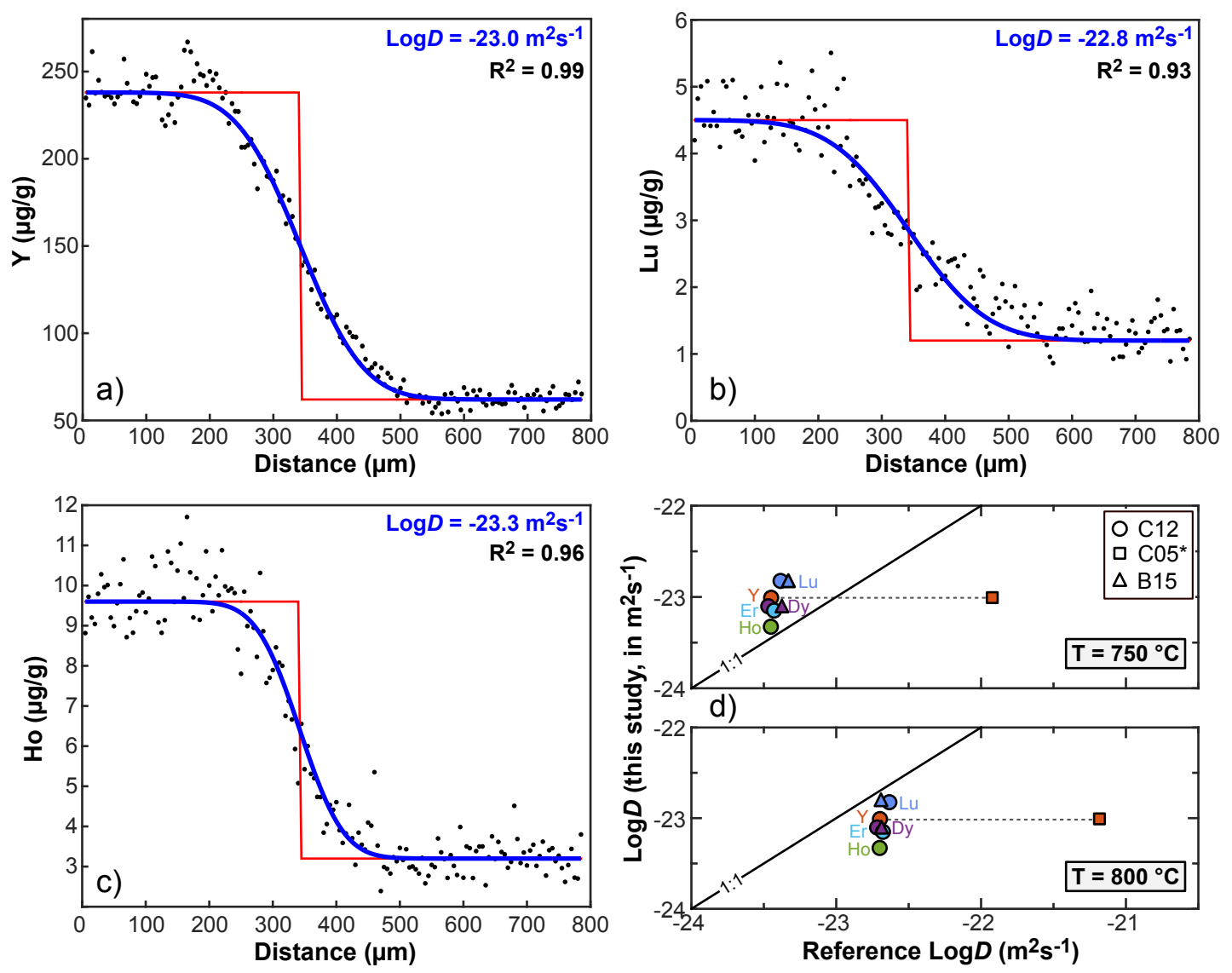

Fig. 10 Results of diffusion modeling for $\mathrm{Y}, \mathrm{Lu}$ and Ho (a-c) using a diffusion time-scale of $10 \mathrm{My}$. The red curve shows the original step function between mantle (left) and core (right). The fitted compositional profile is shown in blue and the obtained diffusion coefficient is reported in each plot as $\log D$. (d) comparison of the determined diffusion coefficients with literature data at $T=$ $750{ }^{\circ} \mathrm{C}$ and $T=800{ }^{\circ} \mathrm{C}$ for a fixed pressure of $1 \mathrm{GPa}$. Abbreviations: C12: Carlson (2012); C05: from Cherniak (2005) published in Carlson (2012); B15: Bloch et al. (2015). See Online Resource for details on the modeling procedure. 
Table S1. Average per-pixel LODs for the LA-ICP-TOFMS sessions.

\begin{tabular}{|c|c|c|c|c|c|}
\hline \multicolumn{2}{|c|}{$\begin{array}{l}\text { CLM6 garnet } \\
\text { Isotope }\end{array}$} & \multicolumn{2}{|c|}{$\begin{array}{l}\text { MG1 garnet } \\
\text { Isotope }\end{array}$} & \multirow{2}{*}{$\begin{array}{l}\text { AV garnet } \\
\text { Isotope } \\
\text { measured }\end{array}$} & \multirow[b]{2}{*}{ LOD in $\mu \mathrm{g} / \mathrm{g}$} \\
\hline measured & LOD in $\mu \mathrm{g} / \mathrm{g}$ & measured & LOD in $\mu \mathrm{g} / \mathrm{g}$ & & \\
\hline${ }^{23} \mathrm{Na}$ & 5000 & ${ }^{23} \mathrm{Na}$ & 1000 & ${ }^{23} \mathrm{Na}$ & 200 \\
\hline${ }^{25} \mathrm{Mg}$ & 3000 & ${ }^{25} \mathrm{Mg}$ & 3000 & ${ }^{25} \mathrm{Mg}$ & 200 \\
\hline${ }^{27} \mathrm{Al}$ & 500 & ${ }^{27} \mathrm{Al}$ & 700 & ${ }^{27} \mathrm{Al}$ & 30 \\
\hline${ }^{29} \mathrm{Si}$ & 50000 & ${ }^{29} \mathrm{Si}$ & 40000 & ${ }^{29} \mathrm{Si}$ & 7000 \\
\hline${ }^{31} \mathrm{P}$ & 600 & ${ }^{31} \mathrm{P}$ & 2000 & ${ }^{31} \mathrm{P}$ & 400 \\
\hline${ }^{34} \mathrm{~S}$ & n.d. & ${ }^{34} \mathrm{~S}$ & 10000 & ${ }^{34} \mathrm{~S}$ & 3000 \\
\hline${ }^{39} \mathrm{~K}$ & 1000 & ${ }^{39} \mathrm{~K}$ & 90 & ${ }^{39} \mathrm{~K}$ & 4000 \\
\hline${ }^{44} \mathrm{Ca}$ & 9000 & ${ }^{44} \mathrm{Ca}$ & 4000 & ${ }^{44} \mathrm{Ca}$ & 400 \\
\hline${ }^{45} \mathrm{SC}$ & 200 & ${ }^{45} \mathrm{SC}$ & 100 & ${ }^{45} \mathrm{Sc}$ & 10 \\
\hline${ }^{49} \mathrm{Ti}$ & 1000 & ${ }^{49} \mathrm{Ti}$ & 800 & ${ }^{49} \mathrm{Ti}$ & 100 \\
\hline${ }^{51} \mathrm{~V}$ & 100 & ${ }^{51} \mathrm{~V}$ & 80 & ${ }^{51} \mathrm{~V}$ & 6 \\
\hline${ }^{52} \mathrm{Cr}$ & 300 & ${ }^{52} \mathrm{Cr}$ & 100 & ${ }^{52} \mathrm{Cr}$ & 10 \\
\hline${ }^{55} \mathrm{Mn}$ & 100 & ${ }^{55} \mathrm{Mn}$ & 100 & ${ }^{55} \mathrm{Mn}$ & 30 \\
\hline${ }^{57} \mathrm{Fe}$ & 4000 & ${ }^{57} \mathrm{Fe}$ & 3000 & ${ }^{57} \mathrm{Fe}$ & 900 \\
\hline${ }^{59} \mathrm{Co}$ & 100 & ${ }^{59} \mathrm{Co}$ & 100 & ${ }^{59} \mathrm{Co}$ & 5 \\
\hline${ }^{60} \mathrm{Ni}$ & 800 & ${ }^{60} \mathrm{Ni}$ & 400 & ${ }^{60} \mathrm{Ni}$ & 30 \\
\hline${ }^{65} \mathrm{Cu}$ & 300 & ${ }^{65} \mathrm{Cu}$ & 200 & ${ }^{65} \mathrm{Cu}$ & 20 \\
\hline${ }^{66} \mathrm{Zn}$ & 400 & ${ }^{66} \mathrm{Zn}$ & 300 & ${ }^{66} \mathrm{Zn}$ & 30 \\
\hline${ }^{71} \mathrm{Ga}$ & 80 & ${ }^{71} \mathrm{Ga}$ & 100 & ${ }^{71} \mathrm{Ga}$ & 6 \\
\hline${ }^{74} \mathrm{Ge}$ & 100 & ${ }^{74} \mathrm{Ge}$ & 100 & ${ }^{74} \mathrm{Ge}$ & 7 \\
\hline${ }^{75} \mathrm{As}$ & 300 & ${ }^{75} \mathrm{As}$ & 300 & ${ }^{75} \mathrm{As}$ & 10 \\
\hline${ }^{77} \mathrm{Se}$ & 4000 & ${ }^{77} \mathrm{Se}$ & 2000 & ${ }^{77} \mathrm{Se}$ & 300 \\
\hline${ }^{85} \mathrm{Rb}$ & 70 & ${ }^{85} \mathrm{Rb}$ & 50 & ${ }^{85} \mathrm{Rb}$ & 20 \\
\hline${ }^{88} \mathrm{Sr}$ & 40 & ${ }^{88} \mathrm{Sr}$ & 20 & ${ }^{88} \mathrm{Sr}$ & 2 \\
\hline${ }^{89} \mathrm{Y}$ & 30 & ${ }^{89} \mathrm{Y}$ & 20 & ${ }^{89} \mathrm{Y}$ & 1 \\
\hline${ }^{90} \mathrm{Zr}$ & 70 & ${ }^{90} \mathrm{Zr}$ & 20 & ${ }^{90} \mathrm{Zr}$ & 3 \\
\hline${ }^{93} \mathrm{Nb}$ & 30 & ${ }^{93} \mathrm{Nb}$ & 20 & ${ }^{93} \mathrm{Nb}$ & 1 \\
\hline${ }^{95} \mathrm{Mo}$ & 200 & ${ }^{95} \mathrm{Mo}$ & 100 & ${ }^{95} \mathrm{Mo}$ & \\
\hline${ }^{103} \mathrm{Rh}$ & 60 & ${ }^{103} \mathrm{Rh}$ & 20 & ${ }^{103} \mathrm{Rh}$ & 1 \\
\hline${ }^{105} \mathrm{Pd}$ & 20 & ${ }^{105} \mathrm{Pd}$ & 10 & ${ }^{105} \mathrm{Pd}$ & 2 \\
\hline${ }^{107} \mathrm{Ag}$ & 30 & ${ }^{107} \mathrm{Ag}$ & 40 & ${ }^{107} \mathrm{Ag}$ & 2 \\
\hline${ }^{111} \mathrm{Cd}$ & 200 & ${ }^{111} \mathrm{Cd}$ & 300 & ${ }^{111} \mathrm{Cd}$ & 9 \\
\hline${ }^{115} \mathrm{In}$ & 20 & ${ }^{115} \mathrm{In}$ & 10 & ${ }^{115} \mathrm{In}$ & 0.6 \\
\hline${ }^{118} \mathrm{Sn}$ & 70 & ${ }^{118} \mathrm{Sn}$ & 50 & ${ }^{118} \mathrm{Sn}$ & 4 \\
\hline${ }^{121} \mathrm{Sb}$ & 40 & ${ }^{121} \mathrm{Sb}$ & 40 & ${ }^{121} \mathrm{Sb}$ & 2 \\
\hline${ }^{125} \mathrm{Te}$ & 2000 & ${ }^{125} \mathrm{Te}$ & 600 & ${ }^{125} \mathrm{Te}$ & 20 \\
\hline${ }^{133} \mathrm{Cs}$ & n.d. & ${ }^{133} \mathrm{Cs}$ & 10 & ${ }^{133} \mathrm{Cs}$ & 0.8 \\
\hline${ }^{137} \mathrm{Ba}$ & 80 & ${ }^{137} \mathrm{Ba}$ & 100 & ${ }^{137} \mathrm{Ba}$ & 5 \\
\hline${ }^{139} \mathrm{La}$ & 10 & ${ }^{139} \mathrm{La}$ & 9 & ${ }^{139} \mathrm{La}$ & 0.6 \\
\hline${ }^{140} \mathrm{Ce}$ & 10 & ${ }^{140} \mathrm{Ce}$ & 9 & ${ }^{140} \mathrm{Ce}$ & 0.6 \\
\hline${ }^{141} \mathrm{Pr}$ & 9 & ${ }^{141} \mathrm{Pr}$ & 7 & ${ }^{141} \mathrm{Pr}$ & 0.4 \\
\hline${ }^{146} \mathrm{Nd}$ & 50 & ${ }^{146} \mathrm{Nd}$ & 40 & ${ }^{146} \mathrm{Nd}$ & 2 \\
\hline${ }^{147} \mathrm{Sm}$ & 50 & ${ }^{147} \mathrm{Sm}$ & 50 & ${ }^{147} \mathrm{Sm}$ & 3 \\
\hline${ }^{153} \mathrm{Eu}$ & 10 & ${ }^{153} \mathrm{Eu}$ & 10 & ${ }^{153} \mathrm{Eu}$ & 0.6 \\
\hline${ }^{157} \mathrm{Gd}$ & 40 & ${ }^{157} \mathrm{Gd}$ & 40 & ${ }^{157} \mathrm{Gd}$ & 2 \\
\hline${ }^{159} \mathrm{~Tb}$ & 6 & ${ }^{159} \mathrm{~Tb}$ & 6 & ${ }^{159} \mathrm{~Tb}$ & 0.3 \\
\hline${ }^{163} \mathrm{Dy}$ & 20 & ${ }^{163} \mathrm{Dy}$ & 30 & ${ }^{163} \mathrm{Dy}$ & 1 \\
\hline${ }^{165} \mathrm{Ho}$ & 5 & ${ }^{165} \mathrm{Ho}$ & 6 & ${ }^{165} \mathrm{Ho}$ & 0.3 \\
\hline${ }^{166} \mathrm{Er}$ & 20 & ${ }^{166} \mathrm{Er}$ & 20 & ${ }^{166} \mathrm{Er}$ & 0.8 \\
\hline${ }^{169} \mathrm{Tm}$ & 5 & ${ }^{169} \mathrm{Tm}$ & 6 & ${ }^{169} \mathrm{Tm}$ & 0.3 \\
\hline${ }^{172} \mathrm{Yb}$ & 20 & ${ }^{172} \mathrm{Yb}$ & 30 & ${ }^{172} \mathrm{Yb}$ & 1 \\
\hline${ }^{175} \mathrm{Lu}$ & 4 & ${ }^{175} \mathrm{Lu}$ & 5 & ${ }^{175} \mathrm{Lu}$ & 0.2 \\
\hline${ }^{178} \mathrm{Hf}$ & 10 & ${ }^{178} \mathrm{Hf}$ & 20 & ${ }^{178} \mathrm{Hf}$ & 1 \\
\hline${ }^{181} \mathrm{Ta}$ & 3 & ${ }^{181} \mathrm{Ta}$ & 4 & ${ }^{181} \mathrm{Ta}$ & 0.4 \\
\hline${ }^{182} \mathrm{~W}$ & 10 & ${ }^{182} \mathrm{~W}$ & 20 & ${ }^{182} \mathrm{~W}$ & 1 \\
\hline${ }^{185} \mathrm{Re}$ & 10 & ${ }^{185} \mathrm{Re}$ & 10 & ${ }^{185} \mathrm{Re}$ & 0.7 \\
\hline${ }^{195} \mathrm{Pt}$ & 30 & ${ }^{195} \mathrm{Pt}$ & 20 & ${ }^{195} \mathrm{Pt}$ & 2 \\
\hline${ }^{197} \mathrm{Au}$ & 10 & ${ }^{197} \mathrm{Au}$ & 10 & ${ }^{197} \mathrm{Au}$ & 0.9 \\
\hline${ }^{205} \mathrm{Tl}$ & 5 & ${ }^{205} \mathrm{TI}$ & 10 & ${ }^{205} \mathrm{Tl}$ & 0.4 \\
\hline${ }^{208} \mathrm{~Pb}$ & 9 & ${ }^{208} \mathrm{~Pb}$ & 10 & ${ }^{208} \mathrm{~Pb}$ & 0.7 \\
\hline${ }^{209} \mathrm{Bi}$ & 4 & ${ }^{209} \mathrm{Bi}$ & 8 & ${ }^{209} \mathrm{Bi}$ & 0.4 \\
\hline${ }^{232} \mathrm{Th}$ & 3 & ${ }^{232} \mathrm{Th}$ & 4 & ${ }^{232} \mathrm{Th}$ & 0.3 \\
\hline${ }^{238} \mathrm{U}$ & 2 & ${ }^{238} \mathrm{U}$ & 3 & ${ }^{238} \mathrm{U}$ & 0.2 \\
\hline
\end{tabular}

n.d. - not determined. Signal intensities for $34 \mathrm{~S}$ and $133 \mathrm{Cs}$ were not detected above baseline levels within the section of the garnet image considered for evaluation. 
Table S2.

LA-ICP-MS spot analyses of MG1 garnet. Mass farctions are given in $\mu \mathrm{g} / \mathrm{g}$.

\begin{tabular}{|c|c|c|c|c|c|c|c|c|c|c|c|c|c|c|c|c|}
\hline -abel & position & rim-core $(\mu \mathrm{m})$ & La & $\mathrm{Ce}$ & $\operatorname{Pr}$ & $\mathrm{Nd}$ & Sm & $\mathrm{Eu}$ & $\mathrm{Gd}$ & $\mathrm{Tb}$ & Dy & Ho & $\mathrm{Er}$ & $\mathrm{Tm}$ & $\mathrm{Yb}$ & Lu \\
\hline UG1_109GTE15 & inner core & 1940 & 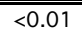 & <<0.03 & (0.005 & 0.23 & (0.83 & (0.13 & (5.0 & 2.8 & 40 & 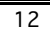 & 42 & (6.0 & 36 & $\overline{\overline{4.3}}$ \\
\hline UG1_092GTE1 & inner core & 1660 & $<0.01$ & $<0.03$ & 0.014 & 0.41 & 0.78 & 0.13 & 5.2 & 2.9 & 38 & 11 & 34 & 4.6 & 27 & 3.5 \\
\hline 1G1_095GTE3* & outer core & 1270 & $<0.01$ & $<0.03$ & 0.008 & 0.42 & 1.2 & 0.11 & 5.4 & 2.0 & 15 & 2.4 & 4.3 & 0.40 & 1.9 & 0.20 \\
\hline G1_098GTE6 & outer core & 880 & $<0.01$ & $<0.03$ & 0.015 & 0.59 & 1.7 & 0.10 & 9.1 & 2.7 & 15 & 2.0 & 3.5 & 0.30 & 1.4 & 0.18 \\
\hline UG1_103GTE10 & mantle & 470 & $<0.01$ & $<0.03$ & 0.037 & 1.08 & 3.9 & 0.15 & 17 & 4.5 & 35 & 7.5 & 23 & 3.5 & 24 & 3.6 \\
\hline UG1_106GTE13 & $\mathrm{rim}$ & 50 & 1.8 & 3.0 & 0.29 & 0.96 & 0.39 & 0.38 & 1.4 & 0.5 & 4.9 & 1.1 & 2.9 & 0.38 & 2.5 & 0.32 \\
\hline
\end{tabular}

* from Hermann and Rubatto, 2003

Trace element analyses were performed by Laser Ablation-ICP-MS at the Research School of Earth Sciences, Australian National University, using a pulsed $193 \mathrm{~nm}$ ArF Ecximer laser with $100 \mathrm{~mJ}$ energy at a repetition rate of $5 \mathrm{~Hz}$ coupled to an Agilent 7500 quadrupole ICP-MS. During the time-resolved analysis of minerals, the contamination from inclusions, fractures and zones of different composition was detected by monitoring several elements and

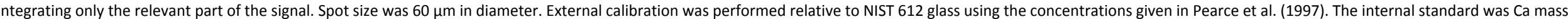
fraction measured by EPMA. Accuracy was assessed to be better than $10 \%$ for all elements by analysing a Columbia River Basalt.

Pearce NJG, Perkins WT, Westgate JA, Gorton MP, Jackson SE, Neal CR, Chenery SP (1997) A compilation of new and published major and trace element data for NIST SRM 610 and NIST SRM 612 glass reference materials. Geostandards Newsletter-the Journal of Geostandards and Geoanalysis 21(1):115-144 
Supplementary Material

Figures and diffusion

Identification of growth mechanisms in metamorphic garnet by high-resolution trace element mapping with LA-ICP-TOFMS

Daniela Rubatto, Marcel Burger, Pierre Lanari, Bodo Hattendorf, Gunnar Schwarz, Christoph Neff, Peter Keresztes Schmidt, Jörg Hermann, Alice Vho, Detlef Günther

2020 - Contributions to Mineralogy and Petrology 

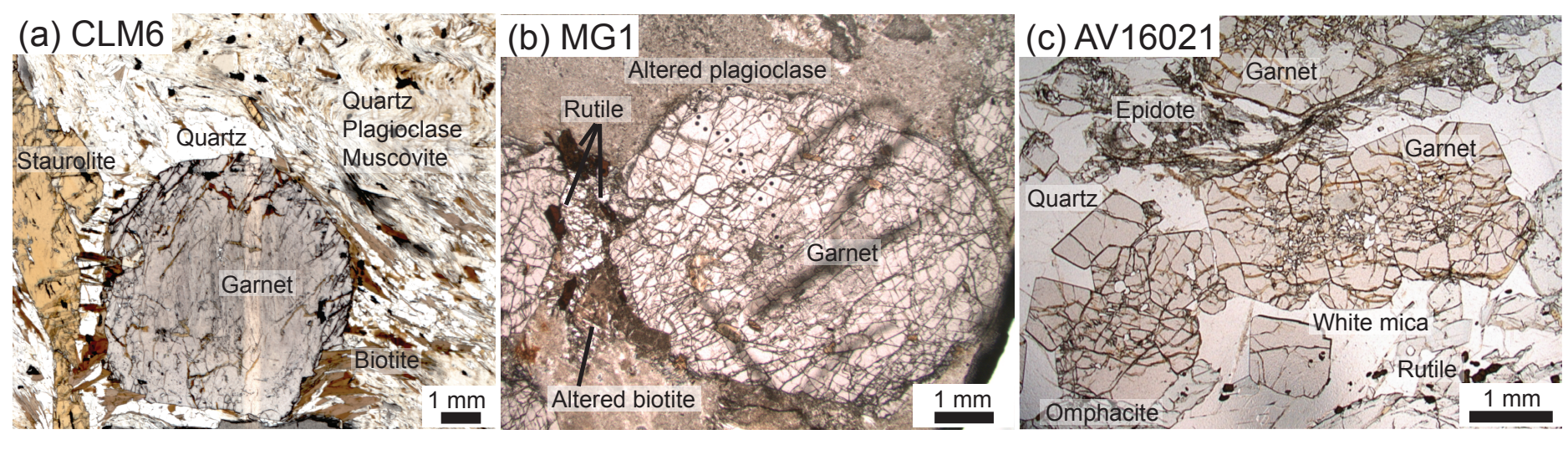

Fig. S1. Photomicrograph of the samples in plain polarized light: (a) CLM6 amphibolite-facies metapelite, (b) MG1 granulite-facies metapelite and (c) eclogite AV16021. The images show the main rock texture, mineral assemblage and the position of the analysed garnet. 


\section{CLM6}
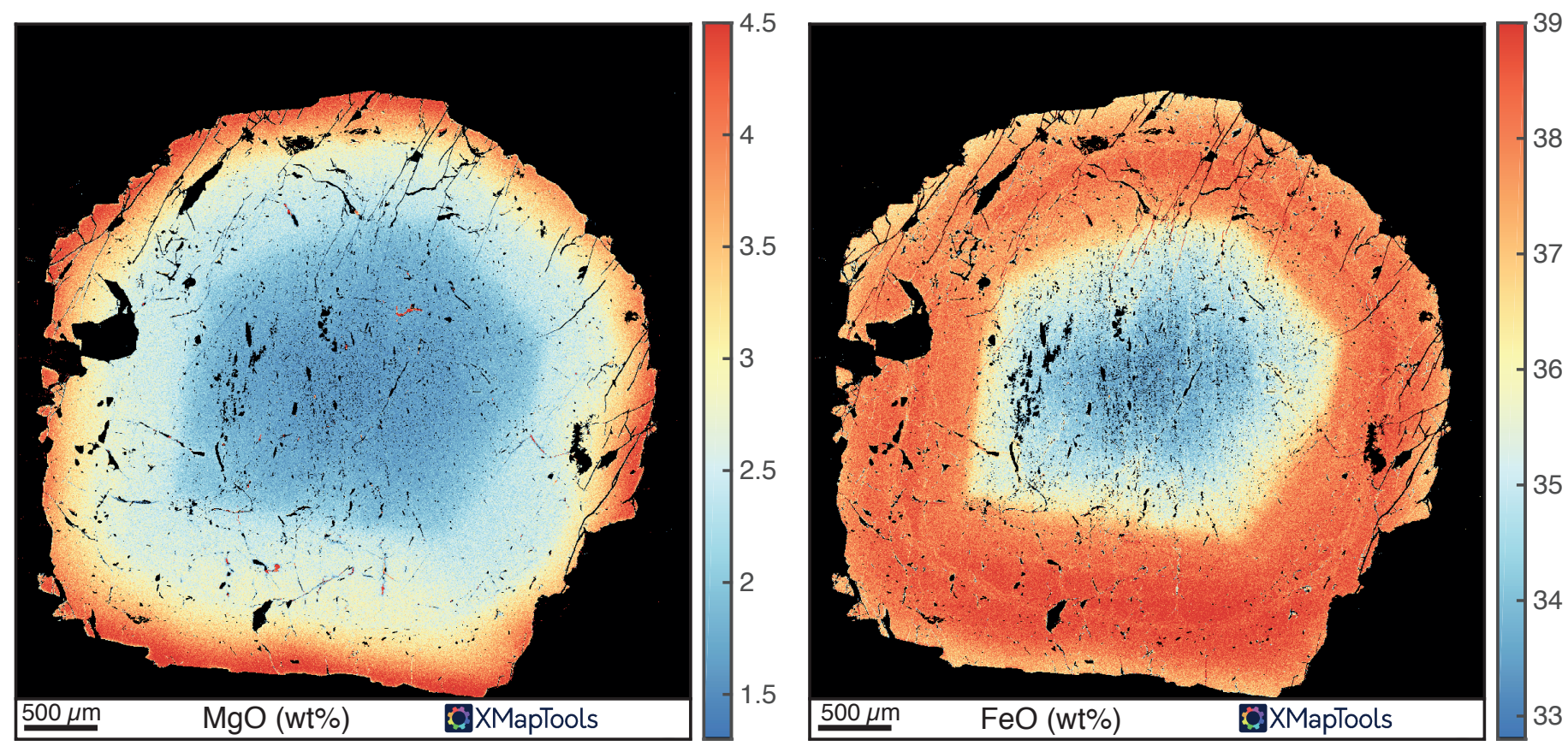

\section{MG1}
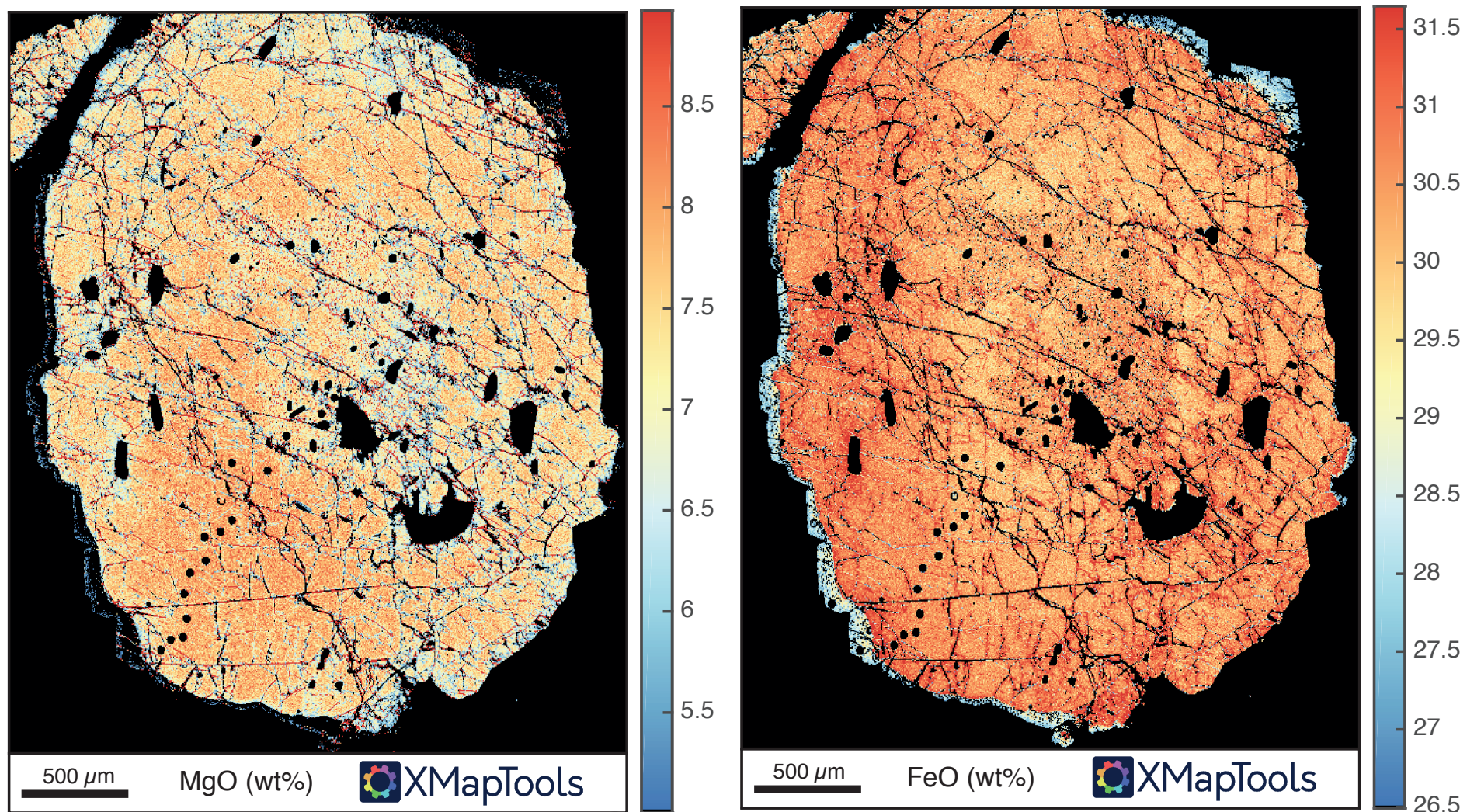

Fig. S2. EPMA MgO and FeO maps for garnet MG1 and CLM6. 

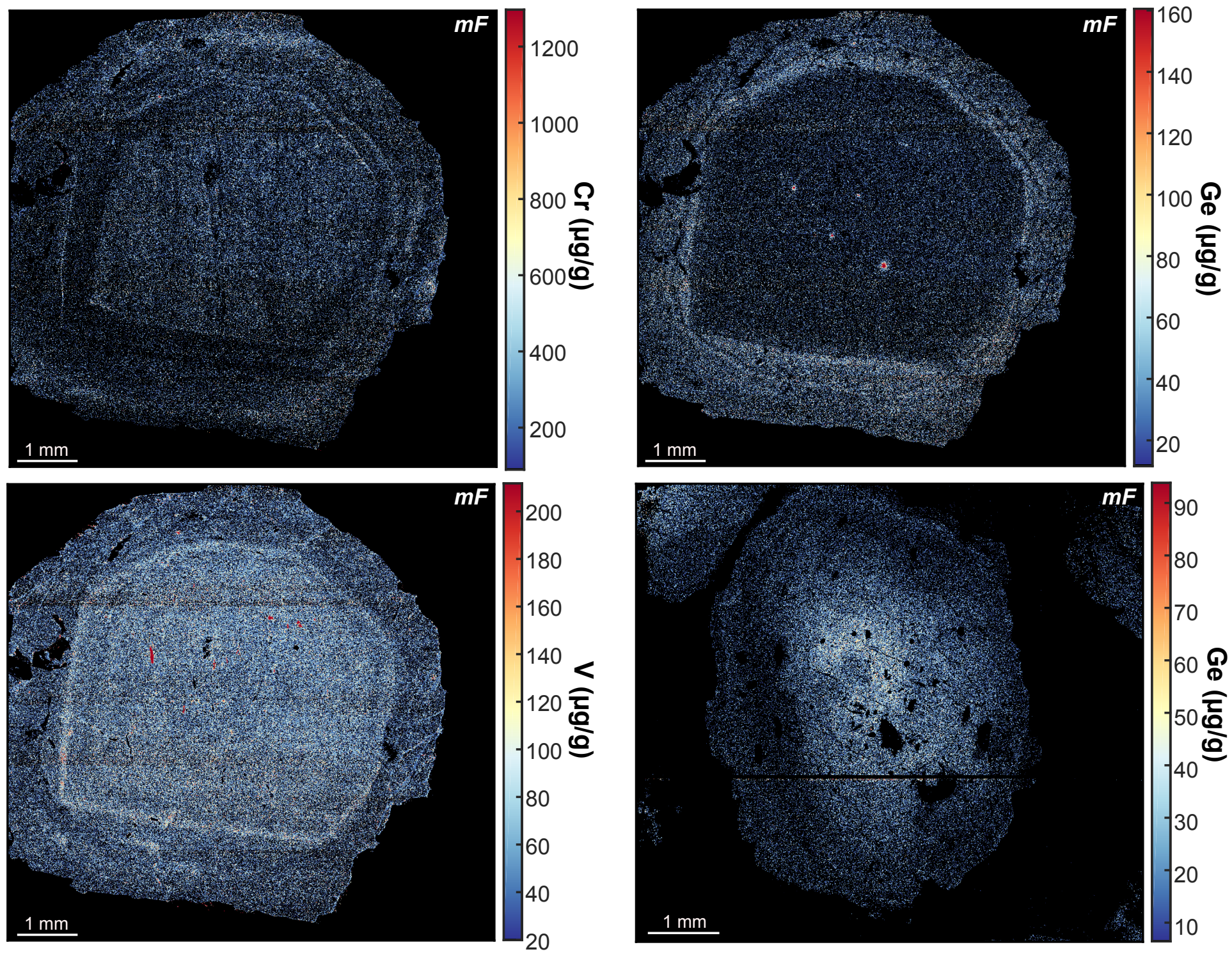

Fig. S3. LA-ICP-TOFMS maps of garnet CLM6 for $\mathrm{Cr}$, Ge and V, and map of garnet MG1 for Ge. 

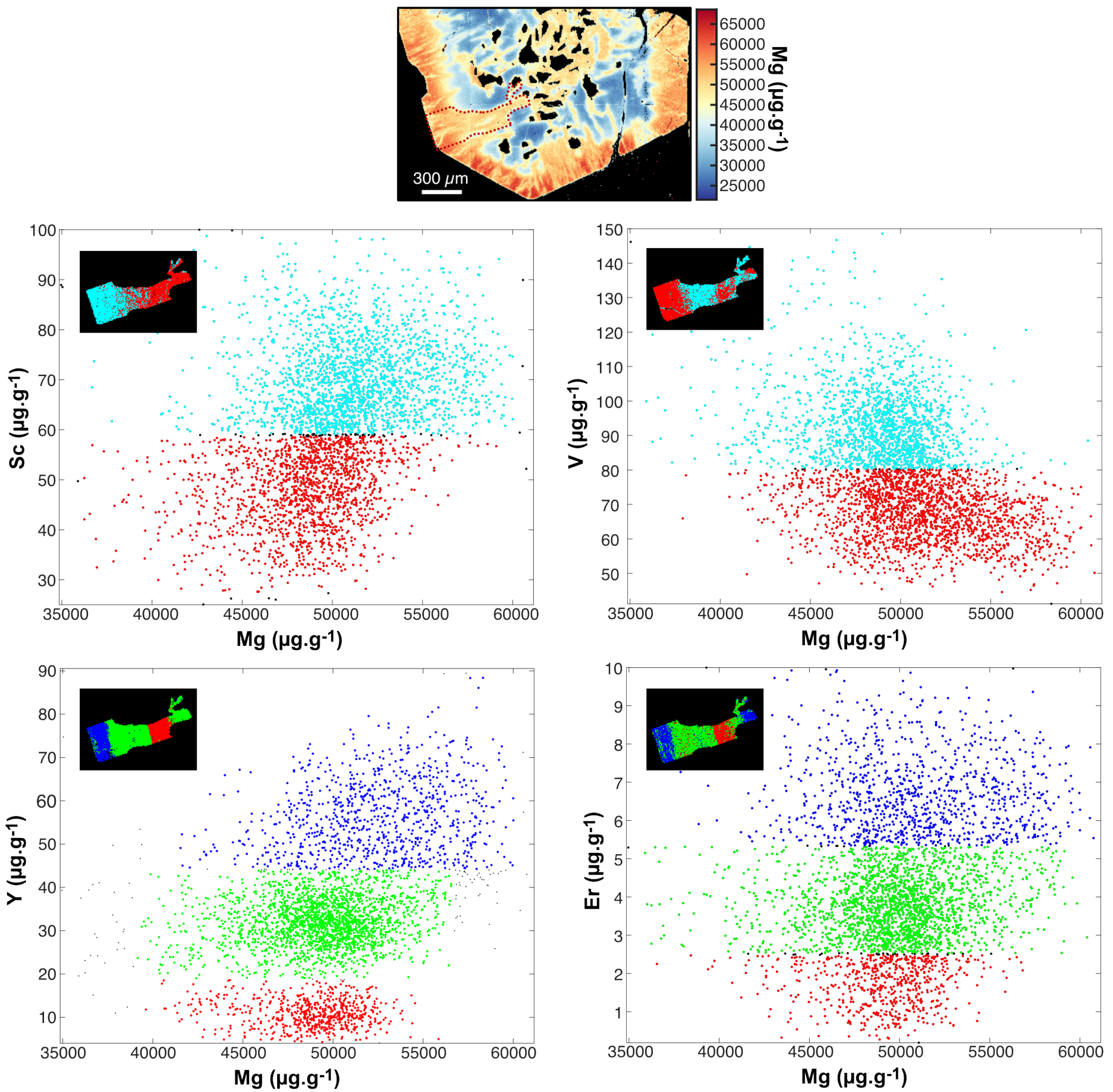

Fig. S4. Divariant diagrams showing the mass fraction of Sc, V, Y and Er versus that of $\mathrm{Mg}$ in an area of eclogitic garnet AV that is rich in secondary veinlets (area marked by dotted red line in the Mg map at the top). The lack of correlation between the trace elements and $\mathrm{Mg}$ is in favour of a selective replacement process (see text for discussion). 


\section{Diffusion models of Y+REE in MG1 garnet}

\section{Formalism}

The diffusion of $\mathrm{Y}+\mathrm{REE}$ was treated as single-component diffusion of elements present in trace concentrations in a homogeneous medium along a one-dimensional semi-infinite profile. As the characteristic diffusion distance $(300-400 \mu \mathrm{m})$ in this example is much smaller than the grain diameter $(\sim 3 \mathrm{~mm})$, the spherical geometry of the crystal was not considered. The model was kept simple in order to achieve order-ofmagnitude estimates. The rate of accumulation (or depletion) was assumed to be dictated by the Fick's $2^{\text {nd }}$ law of diffusion:

$\frac{\partial C}{\partial t}=D \frac{\partial^{2} C}{\partial x^{2}}$

Here, the composition $C$ is expressed in $\mu \mathrm{g} / \mathrm{g}$. The diffusion coefficient $D$ (in $\mathrm{m}^{2} \mathrm{~s}^{-1}$ ) is $T$ and $P$ dependent and defined as $\log _{10} D$ via

$\log D=\log D_{0}+\frac{-\left(E_{a}+P \Delta V\right)}{2.303 R T}$

with $D_{0}$ the pre-exponentioal factor (in $\mathrm{m}^{2} \mathrm{~s}^{-1}$ ), $E_{a}$ the activation energy for diffusion (in $\left.\mathrm{J} \mathrm{mol}^{-1}\right), P$ the pressure (in bar), $\Delta V$ the activation volume $\left(\mathrm{J} \mathrm{bar}^{-1} \mathrm{~mol}^{-1}\right), \mathrm{R}$ the gas constant (8.31 $\left.\mathrm{J} \mathrm{mol}^{-1}\right)$ and $T$ the temperature (in Kelvin).
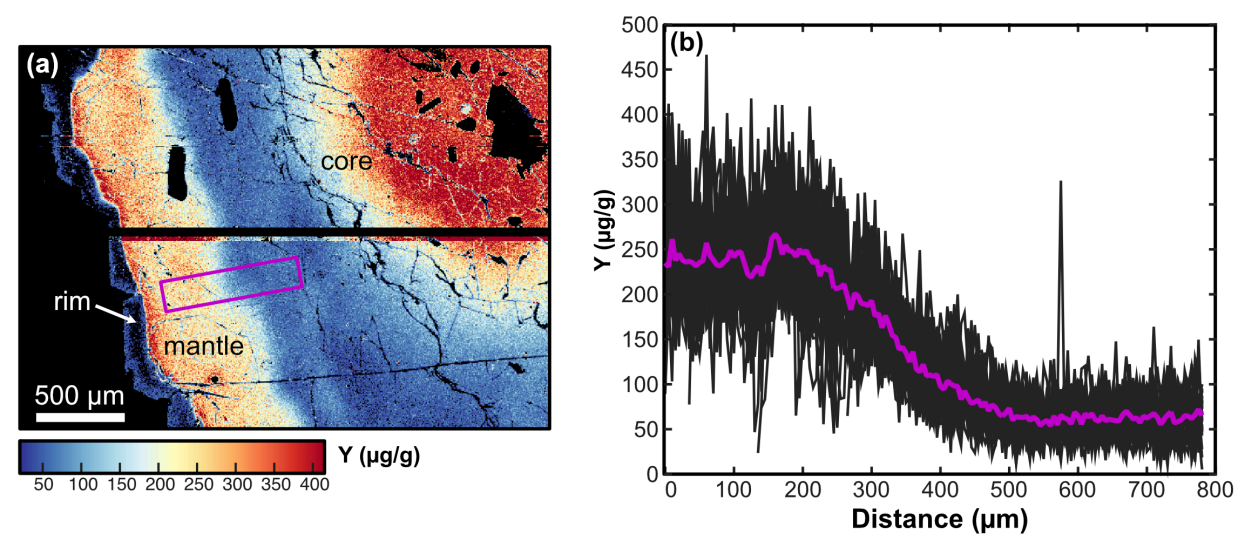

Fig. S5. Extraction of compositional profiles (e.g. for Y) for trace element diffusion modelling using the tool "integrated lines (strip)" in XMAPTOOLS. (a) Map showing the strip position (purple); (b) the individual profiles are shown in black and the average profile in purple. 


\section{Compositional profile, initial geometry and fitting procedure}

Representative compositional profiles for diffusion modelling in garnet MG1 were obtained using the tool "integrated lines (strip)" implemented in XMAPToOLS 3.3.1 (Lanari, et al. 2019; Lanari, et al. 2014). This technique is based on the integration of parallel compositional profiles defining a rectangle, which in this case was located perpendicular to the core-mantle interface (Figure S5a). The average profile is smoother than individual profiles and therefore more suitable for diffusion modelling (Figure S6). The average approach also lowers the LOD for each element compared to the single pixel LOD (Table S1). The compositional profiles of Y, Lu, Ho, Dy and Er were extracted from the same area.

The initial profile for diffusion was generated for each element using a step function; assuming that the compositions in the core and mantle were flat on both side of the interface (initial profile in Fig. S6). This jump in composition was centred on the position $342.5 \mu \mathrm{m}$ set on the basis of Y. This value was kept constant for every element.

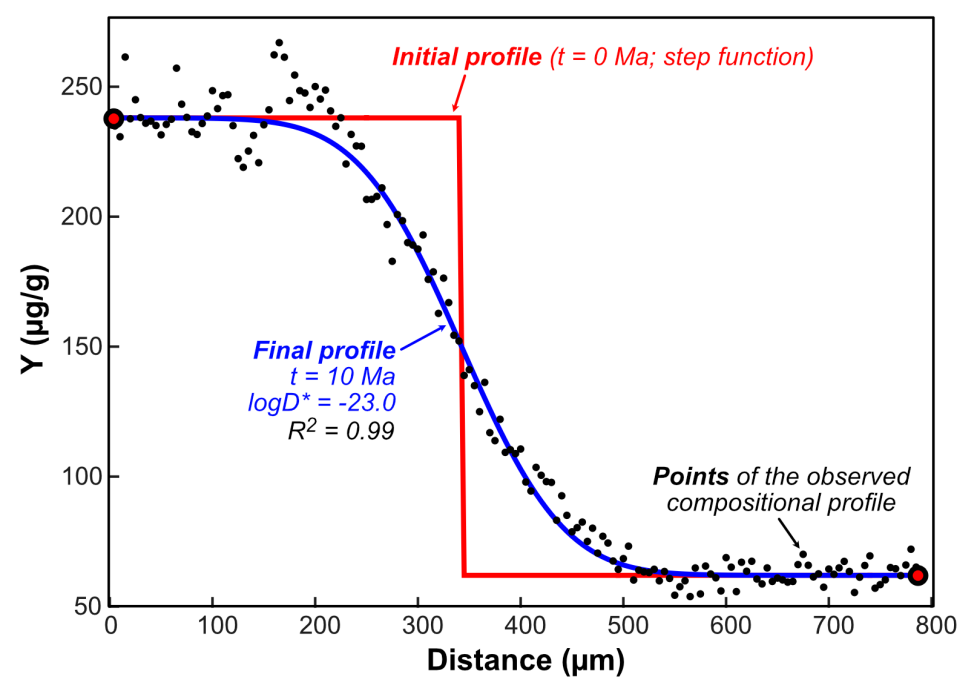

Fig. S6. Diffusion modelling over a period of $10 \mathrm{My}$ for Y. The black spots are the points taken from the average profile (shown in Fig. S5a). The red curve shows the original profile for diffusion modelling defined as a step function between mantle (left) and core (right). The final compositional profile after $10 \mathrm{My}$ is shown in blue; this profile was obtained using the diffusion coefficient expressed in $\log D$. * Fitted (see text). 
The compositional profile after diffusion for a total duration of 10 My divided into 3000 time steps was obtained by solving Equation (1) using a finite difference scheme and a backward time, centred space implicit method. The value of D was obtained by non-linear optimization as the value minimizing the sum of the point-model distances for the $n$ points of the compositional profile defined as

minimize $\sum_{i=1}^{n}\left(C_{i}^{r e f}-C_{i}^{\text {model }}\right)^{2}$

with $C_{i}^{\text {ref }}$ the observed composition and $C_{i}^{\text {model }}$ the model compositions of point $i$ expressed in ppm. As boundary conditions, the compositions at each end of the profile $C_{1}^{\text {model }}$ and $C_{n}^{\text {model }}$ were kept constant (red spots in Figure S2). The inversion allows a value of $D$ to be determined for each element considered (Figure S3; other plots are given in the paper).

The same procedure was repeated for two additional profiles with different locations across the core-mantle boundary. Results are reported in in Table S3 and for Y in Figure S8. The obtained diffusion coefficients (in $\log D$ ) are within $0.1 \log$ unit for $\mathrm{Y}$, Dy and Er and within $0.3 \log$ unit for Lu, Ho.
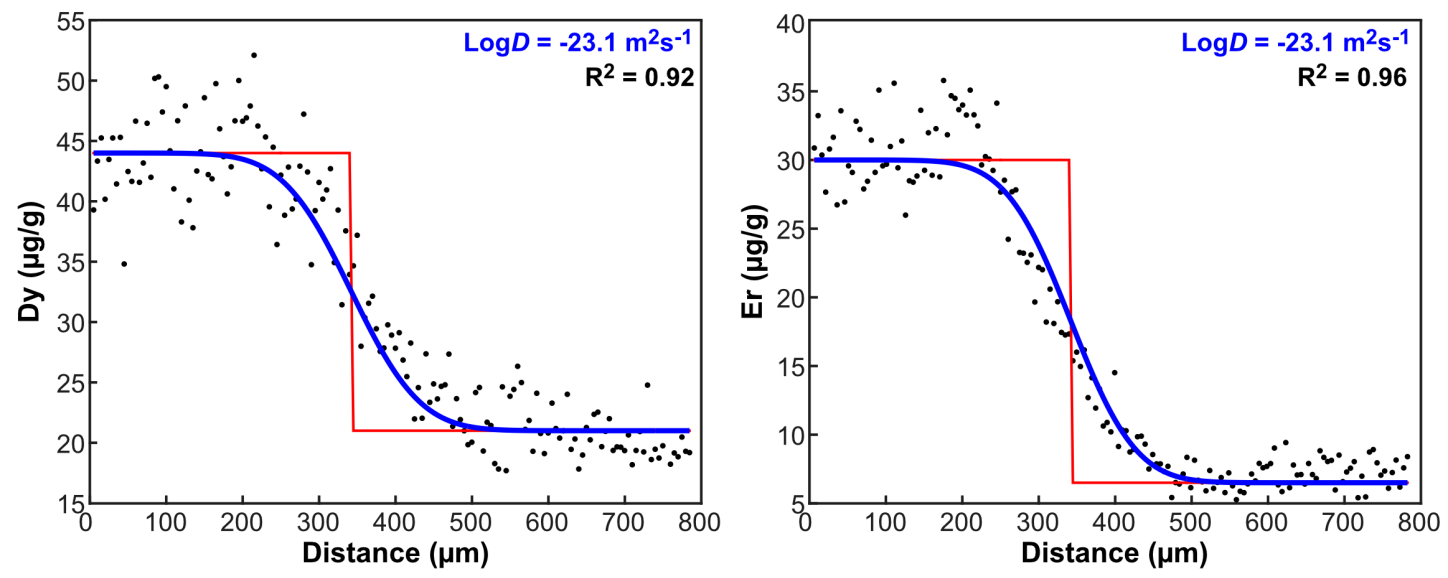

Fig. S7. Diffusion modeling over a period of $10 \mathrm{My}$ for Dy and Er. Other elements are shown in the paper. 

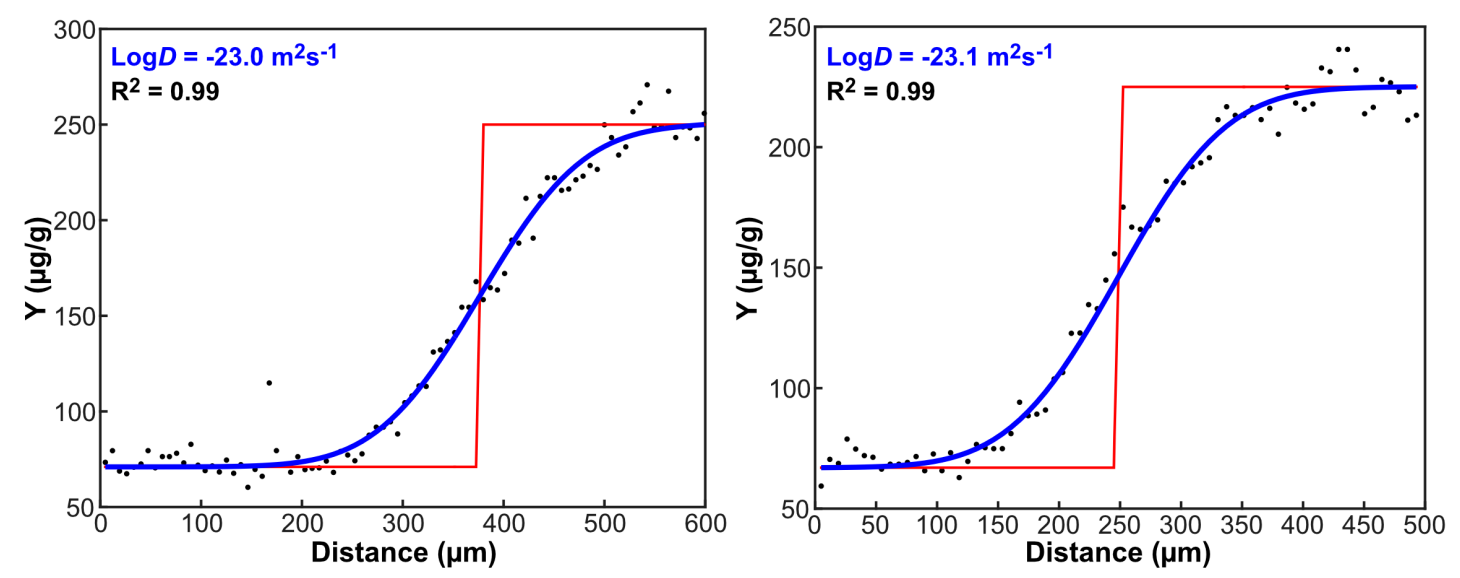

Fig. S8. Diffusion modeling over a period of $10 \mathrm{My}$ for $\mathrm{Y}$ in two additional locations across the core-mantle boundary (from left to right in the profile) of garnet MG1.

\begin{tabular}{lrrr}
\hline & Profile 1 $(\mathrm{T} 2)$ & Profile 2 $(\mathrm{T} 3 \mathrm{~s})$ & Profile 3 $(\mathrm{T} 4)$ \\
\hline $\mathrm{Y}$ & $-23.0\left(\mathrm{R}^{2}=0.99\right)$ & $-23.0(0.99)$ & $-23.1(0.99)$ \\
$\mathrm{Lu}$ & $-22.8(0.93)$ & $-22.8(0.87)$ & $-23.1(0.87)$ \\
$\mathrm{Ho}$ & $-23.3(0.96)$ & $-23.1(0.92)$ & $-23.4(0.95)$ \\
$\mathrm{Dy}$ & $-23.1(0.92)$ & $-23.1(0.86)$ & $-23.2(0.89)$ \\
$\mathrm{Er}$ & $-23.1(0.96)$ & $-23.1(0.91)$ & $-23.2(0.96)$ \\
\hline
\end{tabular}

Table S3. Diffusion coefficients expressed in $\log D$ and $\mathrm{R}^{2}$ values obtained from three diffusion profiles. The reference given within parentheses for each profile is an internal reference corresponding to the fitting experiment.

\section{References}

Lanari P, Vho A, Bovay T, Airaghi L, Centrella S (2019) Quantitative compositional mapping of mineral phases by electron probe micro-analyser. In: Ferrero S, Lanari P, Goncalves P, Grosch EG (eds) Metamorphic Geology: Microscale to Mountain Belts, vol 478. Geological Society of London, Special Publications, pp 39-63

Lanari P, Vidal O, De Andrade V, Dubacq B, Lewin E, Grosch EG, Schwartz S (2014) XMapTools: A MATLABC-based program for electron microprobe X-ray image processing and geothermobarometry. Computers \& Geosciences 62:227-240 doi:10.1016/j.cageo.2013.08.010 